\title{
Defining acoustic emission-based condition monitoring indicators for monitoring piston rod seal and bearing wear in hydraulic cylinders
}

\author{
Vignesh V. Shanbhag ${ }^{1} \cdot$ Thomas J. J. Meyer $^{1} \cdot$ Leo W. Caspers ${ }^{2} \cdot$ Rune Schlanbusch $^{1}$
}

Received: 16 February 2021 / Accepted: 23 May 2021 / Published online: 28 May 2021

(C) The Author(s) 2021

\begin{abstract}
Fluid leakage from hydraulic cylinders is a major concern for the offshore industries as it directly affects hydraulic cylinder energy efficiency and causes environmental contamination. There have been attempts made in literature to develop robust condition monitoring techniques for hydraulic cylinders. However, most of these studies were performed to identify degradation of single components. Therefore, in this study, the aim is to monitor degradation of multiple components simultaneously in hydraulic cylinders using acoustic emissions. Experiments performed consist of three test phases and were performed using a hydraulic test rig. In the first test phase, the study is performed to identify acoustic emission features that can be used to monitor piston rod seal wear. In the second test phase, acoustic emission features are identified that can be used to understand bearing wear when unworn, semi-worn or worn piston rod seals are used in hydraulic test rig. In the third test phase, a run-to-failure test is conducted to identify acoustic emission features that can indicate fluid leakage initiation due to piston rod seal wear. The median frequency feature showed good repeatability in all the three test phases to identify piston rod seal wear, bearing wear and fluid leakage initiation during the initial stages in the hydraulic test rig. The proposed acoustic emission-based condition monitoring technique is robust and can be used for the hydraulic cylinders in the industries, as it identifies acoustic emission features based on particular frequency bands associated to specific components, making it less susceptible to noise from other components.
\end{abstract}

Keywords Hydraulic cylinder · Acoustic emission · Piston rod seal · Bearings · and Median frequency

\section{Introduction}

In hydraulic cylinders, the rod seal system typically consists of a wiper, a primary and secondary rod seal, and rod bearing elements $[1,2]$. The seals deteriorate with continuous use of the

Vignesh V. Shanbhag

vigs@ norceresearch.no

Thomas J. J. Meyer

thme@ norceresearch.no

Leo W. Caspers

leo.caspers@boschrexroth.nl

Rune Schlanbusch

rusc@norceresearch.no

1 Norwegian Research Centre, Jon Lilletuns Vei 9 H, 3. etg, 4879 Grimstad, Norway

2 Bosch Rexroth B.V., Kruisbroeksestraat 1, 5281 RV Boxtel, The Netherlands hydraulic cylinders. If a seal is not replaced in time, there will be fluid leakage. Fluid leakage in hydraulic cylinders is of two types: internal fluid leakage and external fluid leakage [3]. Internal fluid leakage can cause (a) reduction in force exerted by the hydraulic cylinder, (b) instability of the piston rod movement, and (c) reduction in linear velocity. External fluid leakage due to piston rod seal wear can result in (d) increase in risk of injury to work due to fluid spilling, (e) risk of health problems, (f) risk of fire hazard, (g) environmental contamination and all the causes listed due to internal leakage (a)-(c) [4]. Also, the economy consequences of fluid leakage are very high. Alone in North America, every year 100 million gallons of fluid can be saved if external fluid leakage is eliminated [5]. Considering the high consequences of fluid leakage on economy and productivity $[5$, 6], it is important to at least minimise the fluid leakage from hydraulic cylinders, if not eliminating fluid leakage totally. The visual inspection of the seal quality without stopping the hydraulic cylinder is difficult as the seals are concealed within the hydraulic cylinder. Therefore, to avoid unpredictable failure of the piston rod seal or the hydraulic cylinder as a whole, condition 
indicators are required that can indicate health of critical components such as bearings, seal quality, and fluid leakage initiation.

There have been numerous attempts made in the scientific literature to identify sensor-based features that can be used to monitor internal or external fluid leakage due to seal wear. Pressure sensors are widely used in literature to monitor fluid leakage in hydraulic cylinders. For example, An et al. [7] used the extended Kalman filter (EKF) to analyse the pressure data and proposed a residual pressure error feature to monitor the fluid leakage in hydraulic cylinders. The residual pressure error feature calculated between the measured and estimated pressure lines increased with increase in the fluid leakage. Goharrizi et al. $[3,8]$ analysed the pressure using a Daubechies $8(\mathrm{db} 8)$ wavelet as part of the wavelet transform technique. Root mean square (RMS) feature was extracted from the level two detail coefficient to monitor internal fluid leakage, and the RMS feature was extracted from level four detail coefficient to monitor external fluid leakage. The RMS feature proposed in this study was capable to monitor internal fluid leakage in range of $0.2-$ $0.25 \mathrm{~L} / \mathrm{min}$ and external fluid leakage as low as $0.3 \mathrm{~L} / \mathrm{min}$. The RMS feature value decreased with an increase in internal and external fluid leakage. In the other work, Goharrizi et al. [9] analysed pressure data using the Hilbert Huang transform (HHT) technique. Instantaneous magnitude of the first intrinsic mode function (IMF) was observed to be sensitive to detecting fluid leakage of $0.124 \mathrm{~L} / \mathrm{min}$ during offline diagnosis and 0.23 $\mathrm{L} / \mathrm{min}$ during online diagnosis. Zhao et al. [10] used the wavelet packet transform (WPT) technique to analyse pressure data. From the WPT analysis, energy variance, energy value of level 4 and entropy features were proposed to monitor the fluid leakage. Energy variance was observed to be highly sensitive for monitoring fluid leakage compared to the other features extracted from the WPT analysis. Tang et al. [11] used a hybrid method based on the wavelet transform technique and back propagation neural network (BPNN) to analyse pressure data. Energy from different frequency bands was extracted from the wavelet decomposition of pressure data and was constituted as eigen vectors. Then, the eigen vectors were fed as inputs to the BPNN to classify good, moderate and severe fluid leakage conditions. Similarly, Jin et al. [12] performed seal wear classification using wavelet transform and wavelet neural network (WNN). Performance of WNN was compared with BPNN, where higher classification accuracy was observed for WNN in classifying healthy seals and different severities of seal wear classes. Zhao et al. [13] performed multi-sensor monitoring of seal wear in hydraulic cylinders using a combination of fibre Bragg grating (FBG) sensor, fluid pressure sensor and reciprocating displacement sensor. Marginal index feature from FBG sensor, and energy entropy feature from pressure signal and reciprocating displacement signal was observed to be highly sensitive in monitoring seal wear. During fluid leakage in hydraulic cylinders, apart from change in pressure, hydraulic cylinders also exhibit change in vibration or noise. To monitor the change in vibration during fluid leakage, Tan et al. $[14,15]$ and Yunbo et al. [16] used vibration sensors. The vibration energy feature (dBVrms) extracted from the vibration data was used to monitor changes in loading conditions and the amplitude spectrum analysed from the vibration data was used to monitor seal wear conditions. With the increase in loading conditions, an increase in the $\mathrm{dBV}$ rms feature was observed. When the experiments were performed using new piston seals, a new amplitude peak was observed at $99.6 \mathrm{~Hz}$ in the amplitude spectrum. To simulate the worn seal condition, experiments were performed without a piston seal. Without piston seal, an amplitude peak was observed at $48.8 \mathrm{~Hz}$ while the previously observed amplitude peak at $99.6 \mathrm{~Hz}$ was no longer observed in the spectrum. Apart from vibration sensors, use of torque sensors to monitor the seal condition has been demonstrated in literature. Ramachandran et al. $[17,18]$ studied fluid leakage due to ageing of rotary seals using torque sensors. Different time-domain features were extracted from the torque data. With the increase in seal ageing, torque features such as mean, RMS, peak and square mean rooted absolute amplitude (SRA) decreased, whereas torque features such as impulse factor, crest factor and margin factor increased with an increase in seal ageing.

In recent times, acoustic emission (AE) sensors have been used to identify fluid leakage due to piston rod seal wear in hydraulic cylinders. Due to the broad frequency range of $\mathrm{AE}$ sensors, one sensor permits the study of simultaneous tribological characteristics of wear and fault diagnosis of different components in one equipment [19-21]. Chen et al. [22, 23] monitored internal fluid leakage (less than $1 \mathrm{~L} / \mathrm{min}$ ) due to seal wear in water hydraulic cylinders using AE. Time-domain features such as RMS and count rate, and frequency-domain techniques such as power spectral density (PSD) were used to monitor fluid leakage. Energy-based features such RMS were observed to be sensitive for monitoring fluid leakage compared to count rate and PSD. In the PSD spectrum, the fluid leakage was observed to be dominant in the frequency range of $50-300 \mathrm{kHz}$, peaking at $120 \mathrm{kHz}$. Shanbhag et al. [24] monitored fluid leakage at different pressure and speed conditions using AE. The AE data was analysed using time- and frequency-domain features. $\mathrm{AE}$ features such as bandpower and PSD showed good sensitivity for identifying unworn, semi-worn and worn piston rod seals at all the pressure conditions. In the other work, to segregate the noise of other parts that are present in hydraulic test rig, Shanbhag et al. [25] applied the bandpass filtering on the AE data to extract features from the filtered frequency band. The frequency band related to seal wear was observed to be in the frequency range of 50-100 kHz. RMS, peak, bandpower, mean frequency and median frequency showed capability in identifying unworn and worn piston rod seal conditions at different speeds and pressures. Zhang et al. [26] monitored internal leakage in gashydraulic pressurised cylinders using $\mathrm{AE}$ at different loads. The optimization deep belief network (DBN) combined with 
the complete ensemble empirical mode decomposition with adaptive noise (CEEMAN) technique was used to analyse the AE signals. The raw AE signals were decomposed into set of intrinsic mode functions (IMFs) by using CEEDMAN. The AE signal reconstructed from the IMFs was used as input to the optimization DBN and later the particle swarm optimization simulated annealing (PSOSA) algorithm was used to classify four types of internal leakages: no internal leakage, small internal leakage, medium internal leakage and large internal leakage. Using the proposed DBN and CEEDMAN technique, a classification accuracy of $93.6 \%$ was achieved. Towsyfyan et al. [27] performed tribology studies of mechanical seals on a test rig using AE. The AE RMS feature was used to identify defective and healthy seal conditions at different speed and pressure conditions. From literature, AE sensors have successfully been used to monitor piston rod seal wear at different parametric conditions. Therefore, in this study, AE is preferred because of the high frequency range $[28,29]$, which makes it easier to identify wear of different parts that are present in hydraulic cylinders, and to define condition indictors that can be used to simultaneously monitor the condition of multiple components in hydraulic cylinders.

From the above literature, we can note that several works have been conducted to identify fluid leakage due to seal wear using different sensor-based features. Therefore, there is a need for further research using $\mathrm{AE}$, to identify wear of multiple components in the hydraulic cylinder and to further identify fluid leakage due to seal wear during the run-to-failure test. In this study, additional investigation is conducted for the following reasons: (a) can we identify the AE frequency information related to different components that are present in hydraulic cylinders? (b) After identifying the AE frequency information of each components, can we extract $\mathrm{AE}$ features based on frequency bands to identify wear of the different components such as seals and bearings? (c) Can we identify AE-based features that can be used to monitor the fluid leakage initiation point during continuous operation of the hydraulic cylinder? To the best of author's knowledge, these research questions are not answered in the literature. Therefore, to cover these knowledge gaps in the literature, the authors have conducted additional investigation on a customised hydraulic test rig using $\mathrm{AE}$ sensors. The experiments were conducted in three phases using AE sensing. In the first phase, the study was conducted to identify different seal wear conditions in the test rig. In the second phase, the study focussed on identifying bearing wear conditions in the test rig under non-leakage and leakage conditions in the test rig. In the third phase, run-tofailure test was conducted to identify $\mathrm{AE}$ features that can indicate fluid leakage in the test rig at very initial stages. Through this experimental study, the AE-based condition monitoring indicator median frequency showed good repeatability in identifying piston rod seal wear and bearing wear at all the pressure conditions, and the ability to identify initial stages of fluid leakage, and can thus be used to monitor bearing wear and fluid leakage initiation due to piston rod seal wear.

\section{Methodology}

\subsection{Details of hydraulic test rig and experiments}

In this study, experiments were conducted on a hydraulic test rig that closely replicates piston rod movement through the cylinder head, and the fluid leakage conditions that are normally observed in hydraulic cylinders. Figure 1a) represents the hydraulic test rig used to perform condition monitoring in this study. The hydraulic test rig consists of an electromechanical cylinder (containing servomotor, spindle and piston rod), a pressurised flange and a hydraulic power pack. The electromechanical cylinder uses a spindle and nut to convert rotational to translational motion and the servomotor to drive the a)

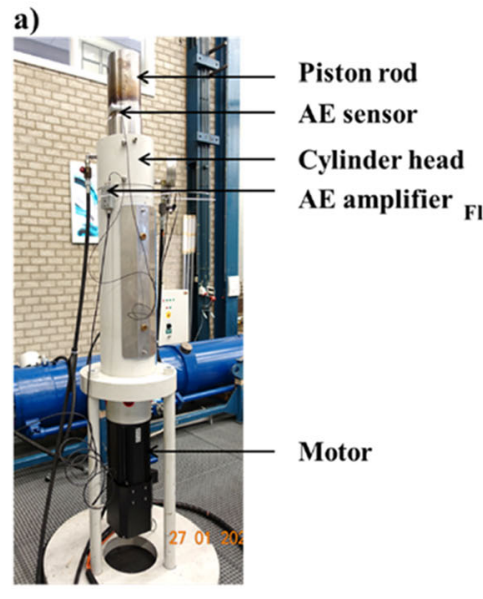

b)

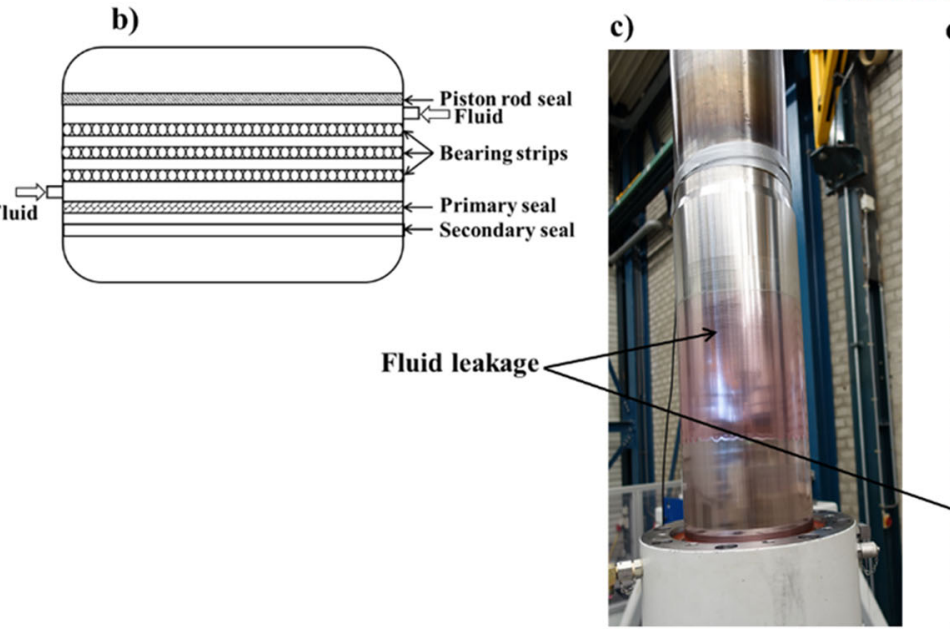

d)

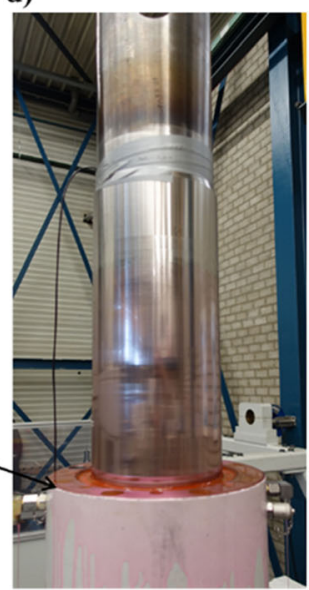

Fig. 1. a Hydraulic test rig; $\mathbf{b}$ schematic view of cylinder head; fluid leakage due to presence of $\mathbf{c}$ semi-worn and $\mathbf{d}$ worn seal in the test rig 
Piston rod seals

a)

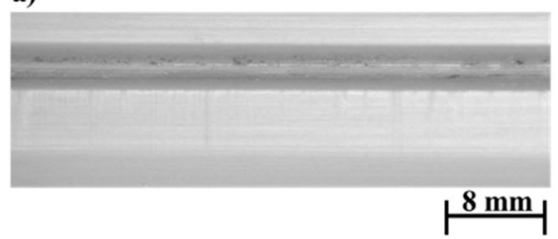

b)

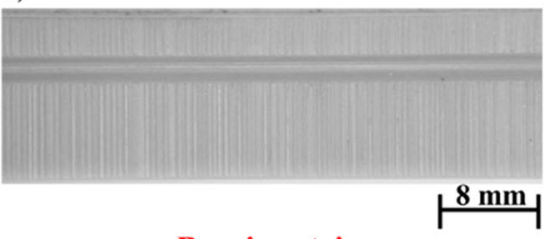

d)

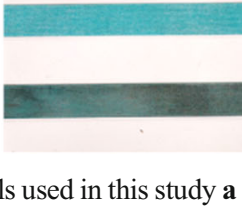

Fig. 2 Microscopic camera images of piston rod seals used in this study a unworn, b semi-worn, c worn, $\mathbf{d}$ camera image of bearing strips used in this study. (Note: Instrument used to take close up image of unworn, semi-worn and worn piston rod seal: Jenoptik ProgRes SpeedXT Core

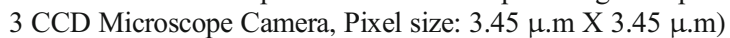

spindle. The driven nut is connected to the piston rod. The piston rod passes through the pressurised flange that contains elements such as bearing strips and seals that are normally present in the hydraulic cylinder head. The motor is equipped with an encoder to control the rod position. As shown in Fig. $1 \mathrm{~b})$, the piston rod seals are placed at both ends of the cylinder head to prevent the fluid leakage and the bearing strips are placed in the cylinder head to withstand arising side and bending loads which are not present in this test rig. The hydraulic power pack supplies pressurised fluid to the flange. The pressure in the flange is controlled by a pressure control valve.

In industries, grooves are observed on the piston rod seal due to presence of abrasive contaminants in the hydraulic fluid [30]. In this condition monitoring study of piston rod seals, only the top piston rod seal placed in the cylinder head (Fig. 1b)) was replaced with unworn, semi-worn and worn piston rod seal. The unworn piston rod seal had no grooves, the semi-worn piston rod seal had minor grooves, and worn piston rod seal had major grooves on its surface (Fig. 2a)-c)). Fluid leakage was observed for all the experiments when semi-worn and worn piston rod seals were used in the test rig (Fig. 1c)-d)). Fluid leakage was observed only on the piston rod when semi-worn piston rod seal was used in the test rig (Fig. 1c)). When a worn piston rod seal was used, fluid leaked out of the cylinder head and was also observed on the piston rod (Fig. 1d)). To perform the condition monitoring study of bearing strips, all the three bearing strips placed in the cylinder head (Fig. 2d)), were replaced with worn bearing strips. Unworn bearing strips have no scars on their surfaces, whereas worn bearing strips had severe scars on their surfaces.

The experiments in this study were performed in three phases. In the first phase, a piston rod seal wear study was performed to identify AE features that can show the difference between unworn, semi-worn and worn piston rod seals in the test rig. In the second phase, a bearing wear study was performed to identify the AE features that can identify unworn and worn bearing conditions in the test rig when unworn, semi-worn and worn piston rod seals were used in the test rig. In the third phase, a run-to-failure test was conducted to identify the AE features that can identify the leakage initiation point during the initial stage of the piston rod seal wear. All the experiments in the first and second phases were performed at pressure conditions of $10,20,30$ and 40 bar. The run-tofailure test experiment in third phase was performed at a pressure condition of 40 bar. In phase three, a premium grade modified polytetrafluoroethylene (PTFE) piston rod seal was used because it fails within a few hours compared to other piston rod seal materials such as polyether-based polyurethane elastomer which have typically long working life. Hydraulic test rig details and process parameters that were used in this study are summarised in Tables 1 and 2 respectively.

\subsection{Details of experiments performed to identify AE frequency band of piston rod seal and bearings}

To quantitatively identify the AE frequency band related to piston rod seal and bearings, experiments were conducted by unclamping the spindle from the piston rod or by removing

Table 1 Hydraulic test rig details

\begin{tabular}{|c|c|c|}
\hline Parameters & Specifications & Supplier \\
\hline Setup & Hydraulic test rig & $\begin{array}{l}\text { Custom made by } \\
\text { Bosch Rexroth } \\
\text { BV }\end{array}$ \\
\hline $\begin{array}{l}\text { Coating on } \\
\text { piston } \\
\text { rod }\end{array}$ & Cladded coating of a cobalt based alloy & $\begin{array}{l}\text { Enduroq }{ }^{\circledR} 3 \text { by } \\
\text { Bosch Rexroth } \\
\text { BV }\end{array}$ \\
\hline Bearings & Orkot Slydring (C380 grade) & $\begin{array}{l}\text { Trelleborg } \\
\text { solutions }\end{array}$ \\
\hline Fluid & Water glycol (ISO 12922) & $\begin{array}{l}\text { Houghton } \\
\text { International }\end{array}$ \\
\hline $\begin{array}{l}\text { Seal } \\
\text { material }\end{array}$ & $\begin{array}{l}\text { Polyether-based polyurethane } \\
\text { elastomer (Z52 grade) and Premium } \\
\text { grade modified PTFE (T05 grade) }\end{array}$ & $\begin{array}{l}\text { Trelleborg } \\
\text { solutions }\end{array}$ \\
\hline
\end{tabular}


Table 2 Process parameters and test details

\begin{tabular}{|c|c|c|c|}
\hline Type of test & Phase 1 - Seal study & $\begin{array}{l}\text { Phase 2-Bearing } \\
\text { study }\end{array}$ & Phase 3-Run-to-failure test \\
\hline Bearing type & Unworn & Unworn, worn & Unworn \\
\hline Seal conditions & $\begin{array}{l}\text { Unworn, semi-worn, } \\
\text { worn }\end{array}$ & $\begin{array}{l}\text { Unworn, semi-worn, } \\
\text { worn }\end{array}$ & Unworn \\
\hline Seal material & \multicolumn{2}{|c|}{$\begin{array}{l}\text { Polyether-based polyurethane elastomer (Z52 } \\
\text { grade) }\end{array}$} & $\begin{array}{l}\text { Premium grade modified PTFE (T05 } \\
\text { grade) }\end{array}$ \\
\hline Speed & \multicolumn{2}{|c|}{$100 \mathrm{~mm} / \mathrm{s}$} & \\
\hline Pressure & \multicolumn{2}{|l|}{$10,20,30,40$ bar } & 40 bar \\
\hline Stroke length & \multicolumn{2}{|l|}{$600 \mathrm{~mm}$} & \\
\hline $\begin{array}{l}\text { Number of } \\
\text { strokes }\end{array}$ & \multicolumn{2}{|l|}{$5(2 \mathrm{~min})$} & $4800(17 \mathrm{~h})$ \\
\hline
\end{tabular}

various components from the test rig to eliminate the $\mathrm{AE}$ signals generated by them. These experiments were performed at zero bar pressure to avoid fluid leakage and damaging the test rig. Details of the experiments are as follows:

1. Without piston rod seal and with piston rod seal in the test rig: To separate the $\mathrm{AE}$ frequency band of the piston rod seal from other components in the test rig, experiments were performed for five strokes with piston rod seal and without piston rod seal in the test rig

2. With unworn and worn bearing strips in the test rig: To identify the AE frequency band related to the bearing wear, experiments were performed for five strokes by operating the test rig with unworn and worn bearing strips. During both experiments, the piston rod seal was removed from the test rig mainly to reconfirm the $\mathrm{AE}$ frequency band related to bearings and piston rod seals.

3. Spindle unclamped from the piston rod: To identify any influence of spindle noise on the AE frequency band related to the piston rod seal, experiments were performed by unclamping the spindle and the piston rod in the test rig. The piston rod was connected to a crane rope and movement of the piston rod was controlled by using the crane remote (see Fig. 3). These experiments were performed for five strokes with and without piston rod seals in the test rig. The experiments performed will also reconfirm the AE frequency band of bearings as there is minimal activity of bearings during these experiments.

4. Machine on and machine off: To identify any influence of servomotor noise on the $\mathrm{AE}$ frequency band, the $\mathrm{AE}$ waveform was recorded for six seconds approximately by having the machine on but in stationary position and completely switched off.

\subsection{AE data acquisition and $A E$ analysis}

In previous studies conducted by Shanbhag et al. [24], the AE frequency band related to seal wear was observed to be between 50 and $100 \mathrm{kHz}$. Therefore, in this study, a wideband
AE sensor with frequency range $(15-1000 \mathrm{kHz})$ is selected for piston rod seal and bearing wear study [31]. For all the experiments, the AE sensor was placed on the piston rod because the piston rod was in directly contact with the piston rod seal and bearings (Fig. 1a)) to ensure strong signal transfer. To record a good $\mathrm{AE}$ waveform path between the piston rod and other parts, the AE sensor was secured on the piston rod using an adhesive bond (Loctite super glue) and industrial tape. The $\mathrm{AE}$ sensor was connected to a pre-amplifier via Bayonet Neill Concelman (BNC) and microdot connectors.

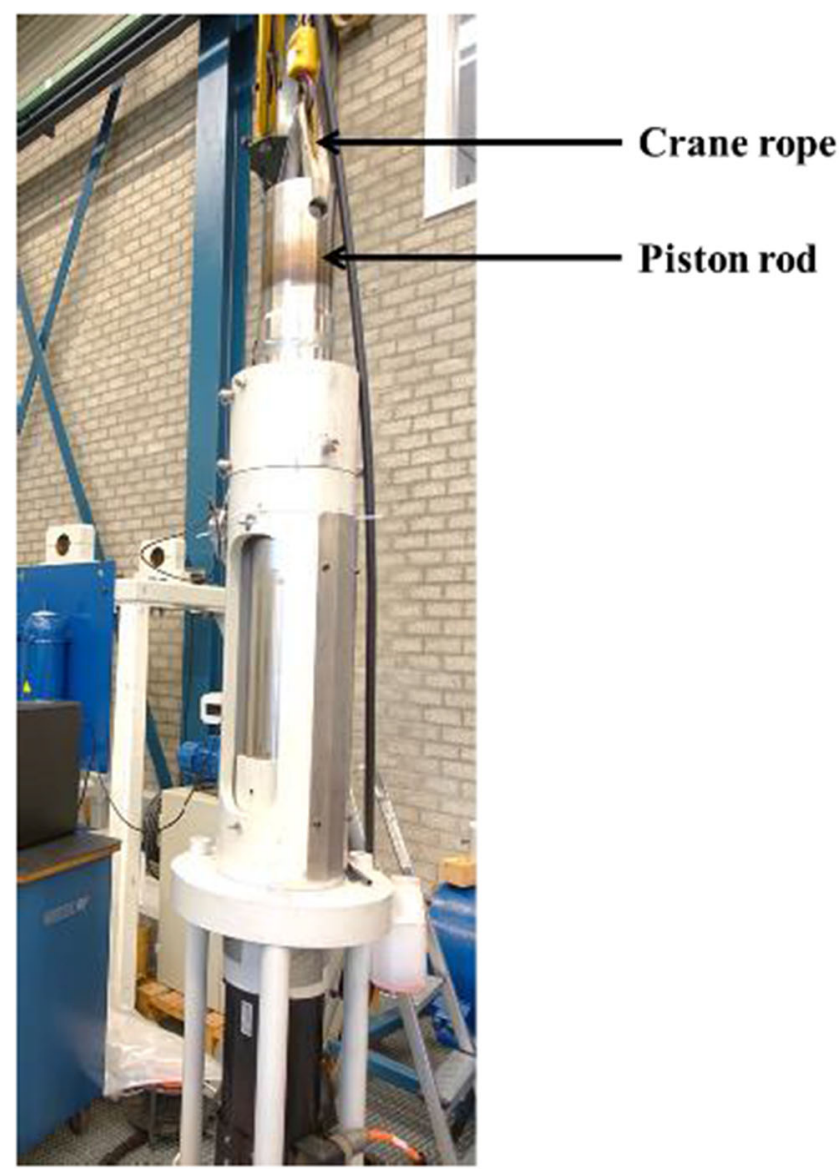

Fig. 3 Experiments performed by unclamping spindle with the piston rod 


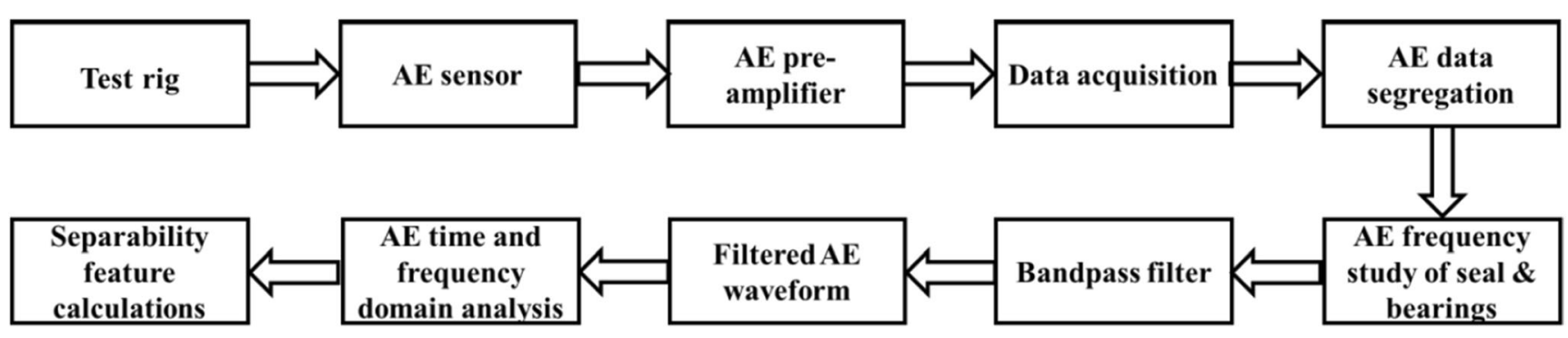

Fig. 4 Methodology adapted for AE data acquisition and AE analysis in this study

The pre-amplifier was connected to the data acquisition board using a 5-m long cable via BNC connectors. To ensure consistency of AE signal recording after every test, Hsu-Nielsen pencil lead break was performed every time when the piston rod seal or the bearing strips were removed from the cylinder head. The methodology of the Hsu-Nielsen pencil lead break test and the results observed is extensively discussed in our previous work $[24,25]$. If the amplitude of the AE signal related to the pencil lead break was not higher compared to that of background noise, then the AE sensor was removed and fixed again with a sufficient amount of adhesive bond.

In the data acquisition software, the $\mathrm{AE}$ waveform can be recorded for long duration and for short intervals. For experiments performed in phase one and phase two, the AE waveform was recorded in the continuous $\mathrm{AE}$ waveform mode for the entire test duration. In phase three, the AE waveform was recorded in the AE burst waveform mode for every 1-s interval because of the high AE data rate $(1 \mathrm{MS} / \mathrm{s})$. During burst mode, the AE data is recorded at $1 \mathrm{MS} / \mathrm{s}$ for $4 \mathrm{~ms}$ at the start of every second. For experiments performed in phases one and two, the continuous AE waveform was recorded. In phase three, only the burst type $\mathrm{AE}$ waveform was recorded because of the high $\mathrm{AE}$ data rate (1
$\mathrm{MS} / \mathrm{s})$. The AE waveform recorded from the experiments in all the three phases was subjected to the bandpass filtering based on the AE frequency band identified for each component. To identify the AE frequency bands of piston rod seals and bearings, the AE waveform recorded from the experiments performed in Section 2.2, was analysed using the PSD plot. Figure 4 represents the flow chart explaining the methodology adapted in this study to perform $\mathrm{AE}$ data acquisition from the test rig and for $\mathrm{AE}$ data analysis. AE equipment and data acquisition details used in this study are summarised in Table 3.

For all the experiments, the AE waveform was recorded for both extension and retraction strokes of the piston rod and segregated based on stroke timing. As the AE waveform content was similar for extension and retraction stroke, only the AE waveform analysis from the extension stroke is presented in this paper. The AE frequency bands of piston rod seals and bearings were used as input for defining the bandpass filter. The filtered AE waveforms were further analysed using different time-domain and frequency-domain features. The AE features were calculated using inbuilt MATLAB functions. To understand the sensitivity and repeatability of each feature, the average of five strokes and its standard deviation were
Table 3 AE equipment and data acquisition details

\begin{tabular}{|c|c|c|c|c|}
\hline Parameters & \multicolumn{3}{|l|}{ Specifications } & Supplier \\
\hline AE sensor & \multirow{2}{*}{\multicolumn{3}{|c|}{$\begin{array}{l}\text { Mid-frequency range (Grade-R15 } \alpha \text { ) } \\
1\end{array}$}} & Physical acoustics \\
\hline Number of AE sensor used & & & & (Mistras) \\
\hline AE frequency range & \multicolumn{4}{|c|}{ 15-1000 kHz (General purpose sensor) } \\
\hline $\begin{array}{l}\text { Peak sensitivity observed in } \\
\text { frequency range }\end{array}$ & \multicolumn{3}{|l|}{$50-400 \mathrm{kHz}$} & \\
\hline Resonant frequency & \multicolumn{3}{|l|}{$150 \mathrm{kHz}$} & \\
\hline AE data acquisition software & \multicolumn{3}{|l|}{ AEwin } & \\
\hline AE data acquisition board & \multicolumn{3}{|c|}{ PCI-2 - PCI-based two-channel AE board \& system } & \\
\hline AE data acquisition & \multicolumn{3}{|l|}{$1 \mathrm{MS} / \mathrm{s}$} & \\
\hline AE pre-amplifier & \multicolumn{3}{|c|}{$\begin{array}{l}2 / 4 / 6 \text { switch selectable gain single ended and differential } \\
\text { pre-amplifier }\end{array}$} & \\
\hline AE pre-amplifier gain & \multicolumn{3}{|l|}{$40 \mathrm{~dB}$} & \\
\hline Type of test & $\begin{array}{l}\text { Phase } 1- \\
\quad \text { Seal study }\end{array}$ & $\begin{array}{c}\text { Phase 2- } \\
\text { Bearing } \\
\text { study }\end{array}$ & $\begin{array}{l}\text { Phase 3- } \\
\text { Run-to-failure } \\
\text { test }\end{array}$ & \\
\hline $\begin{array}{l}\text { Type of AE waveform } \\
\text { recorded }\end{array}$ & Continuous & & Burst & \\
\hline Bandpass filter & $50-100 \mathrm{kHz}$ & $15-30 \mathrm{kHz}$ & $50-100 \mathrm{kHz}$ & \\
\hline
\end{tabular}


calculated at each pressure condition. The mathematical expressions of each time-domain and frequency-domain feature used in this study are represented in Table 4. For the AE features that could identify the difference between unworn or worn part condition, separability percentage was calculated between the initial feature value (unworn part) and final feature value (worn part) to understand the $\mathrm{AE}$ feature that has maximum separability percentage (Table 4 ). The mean of separability percentage is calculated from all the four pressure conditions and are plotted to quantitatively compare the performance of AE features that can be used to understand piston rod seal and bearing wear in the test rig.

Here $x(n)$ represents waveform series for $n=1,2, \ldots . N$, where $N$ represents number of data points, $s(k)$ represents spectrum for $k=1,2 \ldots K$, where $K$ represents number of spectrum lines, $f_{k}$ represents frequency value of the $k^{\text {th }}$ spectrum line, $P_{l}$ represents average power for $l=1,2, \ldots L$, where $L$ represents number of columns and, $f_{1}, f_{2}$ represent the lower and upper limits of the frequency band respectively. $P(t, f)$ represents the power spectrum. $F_{j}$ and $F_{i}$ are two frequency points from each side of the peak with the magnitude 3 $d B=\frac{M_{\max }}{\sqrt{2}} . M_{\max }$ represents maximum magnitude in the frequency plot. $x_{F}$ and $x_{i}$ represent final and initial feature values.

\section{Results}

\subsection{AE waveform and frequency study of piston rod seals and bearings}

In this section, the $\mathrm{AE}$ waveform obtained from the experiments elaborated in Section 2.2 is discussed. The PSD is calculated from the $\mathrm{AE}$ waveform is plotted to understand the $\mathrm{AE}$ frequency band of piston rod seals and bearings. Also, any influence of noise on the AE waveform from other components that are present in test rig, such as the spindle and the servomotor, is discussed.

\subsubsection{AE waveform}

The AE waveforms recorded from the experiments performed to understand the AE frequency band of piston rod seals and bearings are represented in Fig. 5. When the nut is clamped to the piston rod in the test rig, the maximum amplitude of the $\mathrm{AE}$ waveform is in the range of $\pm 1-2 \mathrm{~V}$ (Fig. 5a)-c)), whereas when the nut was unclamped with the piston rod in the test rig, the maximum amplitude of the $\mathrm{AE}$ waveform is in the range of \pm 10 to $40 \mathrm{mV}$ (Fig. 5d)-e)). When the nut was clamped with the piston rod and the machine was in stationary position, the maximum amplitude of the $\mathrm{AE}$ waveform is in the range of \pm 2 to $10 \mathrm{mV}$ (Fig. 5f)-g)). By comparing AE waveforms in Fig. 5a)-c) with that of Fig. 5d)-e), when the nut is clamped with piston rod, a AE burst waveform is present along with the $\mathrm{AE}$ continuous waveform. From qualitative observation in Fig. $5 \mathrm{c}$ ), the number of $\mathrm{AE}$ burst waveforms having worn bearings is higher compared to that with unworn bearings (Fig. 5a)-b)). Also, from the AE waveform represented in Fig. 5f)-g), the influence of machine noise on the $\mathrm{AE}$ waveform is negligible ( \pm 2 to $10 \mathrm{mV}$ ). In Fig. $5 \mathrm{a})-\mathrm{c}$ ), due to a large number of $\mathrm{AE}$ burst waveforms present along with the $\mathrm{AE}$ continuous waveform, it is difficult to correlate the AE waveform with the piston rod seal or bearing wear events. Therefore, a PSD plot is calculated from the $\mathrm{AE}$ waveform to understand the $\mathrm{AE}$ frequency band of the piston rod seal and bearings.

Table 4 Mathematical expression of time-domain and frequency-domain features used in this study [32-37]

\begin{tabular}{|c|c|c|c|}
\hline Time-domain features & Calculation & Frequency-domain features & Calculation \\
\hline Mean & $x_{m}=\frac{\sum_{n=1}^{N} x(n)}{N}$ & Bandpower & $x_{B P}=\sum_{l=f_{1}}^{f_{2}} P_{l}$ \\
\hline Root mean square (RMS) & $x_{r m s}=\frac{\sum_{n=1}^{N} x(n)^{2}}{N}$ & Median frequency & $x_{m e d}=\frac{1}{2} \sum_{k=1}^{K} s(k)$ \\
\hline Peak & $x_{p}=\max |x(n)|$ & Mean frequency & $x_{\text {meanf }}=\frac{\sum_{k=1}^{K} f_{k} s(k)}{\sum_{k=1}^{K} s(k)}$ \\
\hline Standard deviation & $x_{s t d}=\sqrt{\sum_{n=1}^{N}\left(x(n)-x_{m}\right)} \frac{2}{N-1}$ & Peak frequency & $x_{P F}(t)=\operatorname{argmax}_{f} P(t, f)$ \\
\hline Skewness & $x_{\text {skew }}=\sum_{n=1}^{N}\left(x(n)-x_{m}\right) \frac{3}{(N-1) x_{\text {std }}^{3}}$ & Mean peak frequency & $x_{m P F}=\frac{1}{T} \int_{0}^{T} x_{P F}(t) d t$ \\
\hline Kurtosis & $x_{\text {kurt }}=\sum_{n=1}^{N}\left(x(n)-x_{m}\right) \frac{4}{(N-1) x_{\text {std }}^{4}}$ & Power bandwidth & $x_{P B}=\frac{f_{j}-f_{i}}{2 f_{\max }}$ \\
\hline Crest factor & $x_{C F}=\stackrel{x_{p}}{x_{r m s}}$ & & \\
\hline Separability percentage of the feature & & $x_{s p}=\frac{x_{F}-x_{i}}{x_{i}} 100$ & \\
\hline
\end{tabular}




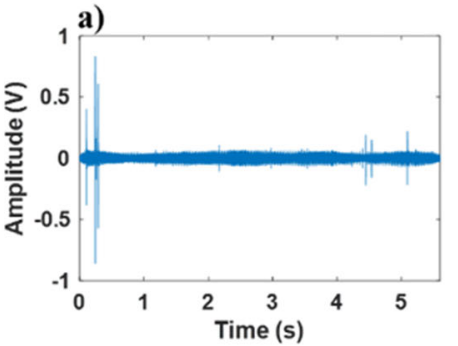

SPINDLE UNCLAMPED b)

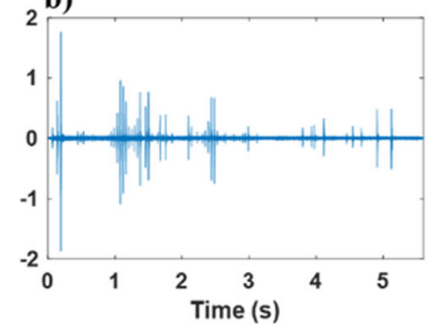

c)

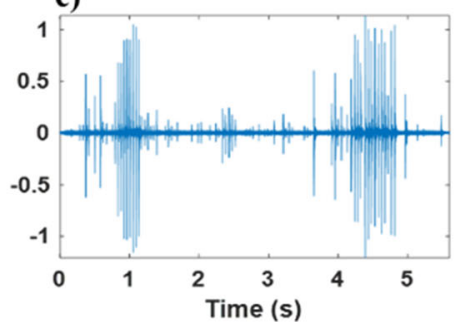

SPINDLE CLAMPED d)

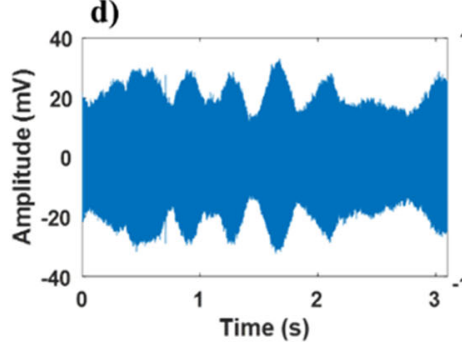

e)

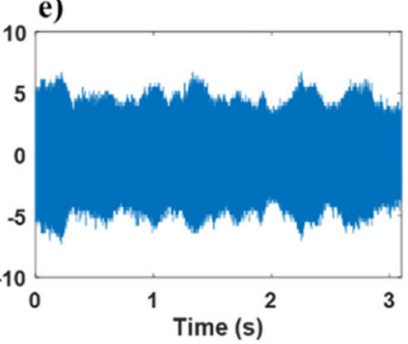

Fig. 5. AE waveform from experiments conducted with spindle clamped with piston rod a with seal and bearings, $\mathbf{b}$ without seal and with bearings, $\mathbf{c}$ without seal and with worn bearings. Nut unclamped from piston rod $\mathbf{d}$

\subsubsection{AE frequency study}

Figure 6 represents the PSD plot calculated from the AE waveform presented in Fig. 5a)-g). When the nut is clamped f)
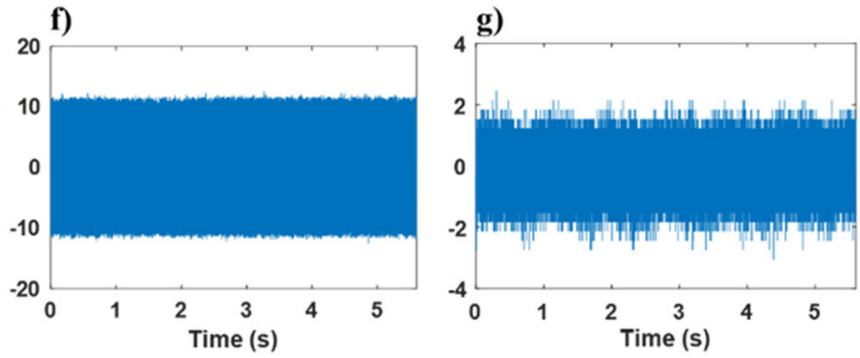

With seal and bearings, $\mathbf{e}$ without seal and with bearings. Nut clamped to piston rod, machine $\mathbf{f}$ on, $\mathbf{g}$ off. (Note: Pressure $=0$, stroke number $=1$ )

to the piston rod in the test rig, the magnitude in the $\mathrm{AE}$ frequency plot is nearly consistent in the frequency band of 15-30 kHz (Fig. 6a)-b)). The magnitude of the PSD plot varies between the $\mathrm{AE}$ frequency band of $50-200 \mathrm{kHz}$ when
Fig. 6. PSD plot calculated for a nut clamped to piston rod (Fig. 5a)-b)), b nut clamped to piston rod (Fig. 5b) and c)). Nut unclamped from piston rod (Fig. 5d)-e)). d Nut clamped to piston rod, machine on and off (Fig. 5f)-g)). (Note: To enhance clarity of images, $y$-scale is plotted in logarithmic scale).
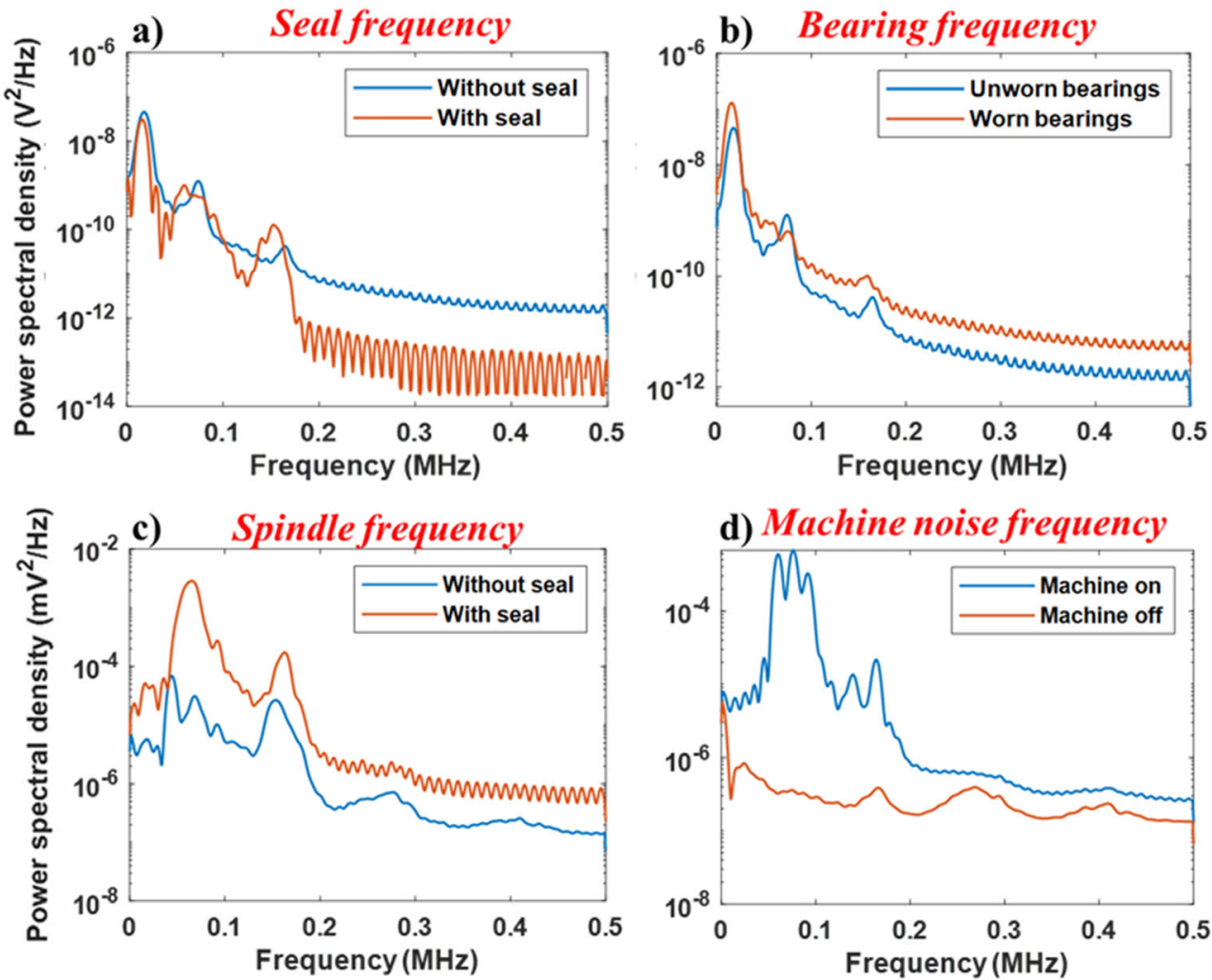

d) Machine noise frequency

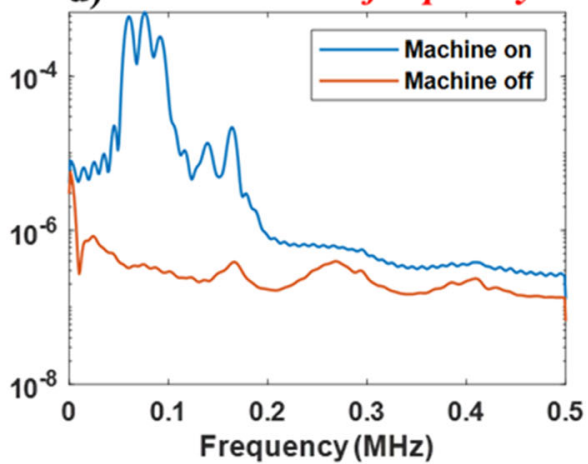


the piston rod seal is removed from the cylinder head (Fig. 6a) and c)). When there are worn bearings present in the test rig, the magnitude of PSD plot varies in the AE frequency band of $15-30 \mathrm{kHz}$ and is higher compared to that of unworn bearings (Fig. 6b)). This is likely because of change in friction conditions at the interface of bearing strips and piston rod [38]. The bearing inactivity can be seen in the AE frequency band of $15-30 \mathrm{kHz}$, when the nut is unclamped from the piston rod $(15-30 \mathrm{kHz})$. When the machine is in stationary position, the maximum magnitude of PSD can be seen in the AE frequency band of $50-200 \mathrm{kHz}$ (Fig. 6d)). The magnitude in the PSD is negligible when the machine is switched off (Fig. 6d)). Based on these observations and previous studies conducted by Shanbhag et al. [24, 25], the piston rod seal wear information can be studied in the AE frequency band of $50-100 \mathrm{kHz}$, and the bearing wear information in the AE frequency band of 15$30 \mathrm{kHz}$. This AE frequency band information is used as input to the bandpass filtering to study piston rod seal and bearing wear.

\subsection{Unfiltered and bandpass filtered AE waveform}

From the experiments performed to monitor piston rod seal wear and bearing wear, a combination of AE burst waveform

Fig. 7. Unfiltered bandpass AE waveform for a unworn seal; $\mathbf{b}$ unworn bearing with unworn seal, bandpass filtered $\mathrm{AE}$ waveform; $\mathbf{c}$ unworn seal; $\mathbf{d}$ unworn bearing with unworn seal. (Note: AE waveform from experiment performed at 20 bar pressure, second stroke, $100 \mathrm{~mm} / \mathrm{s}$ ) and $\mathrm{AE}$ continuous waveform is observed (Fig. 7a)-b)). For the piston rod seal wear study, the AE waveform is passed through the bandpass filter in the AE frequency range of 50 $100 \mathrm{kHz}$ (Section 3.1.2). After bandpass filtering, only the continuous AE waveform can be observed (Fig. 7c)). Similarly, the AE waveform recorded from the bearing wear study is passed through the bandpass filter in the AE frequency range of $15-30 \mathrm{kHz}$ (Section 3.1.2). The presence of $\mathrm{AE}$ burst waveform along with continuous $\mathrm{AE}$ waveform can be observed after bandpass filtering (Fig. 7c)). This bandpass filtering technique was applied to all the $\mathrm{AE}$ waveforms from the piston rod seal wear study ( $60 \mathrm{AE}$ waveforms), the bearing wear study (180 AE waveforms), and the run-to-failure test (approximately 63,000 AE waveforms).

\subsection{Analysis of the AE waveform-piston rod seal wear study}

Figure 8 represents the AE features calculated from the bandpass filtered $\mathrm{AE}$ waveform recorded from phase one (piston rod seal wear study). In time-domain, RMS and peak can be used to identify non-leakage conditions due to unworn piston rod seal and fluid leakage conditions due to semiworn or worn piston rod seal in the test rig (Fig. 8b)-c)).

\section{UNFILTERED AE WAVEFORM}
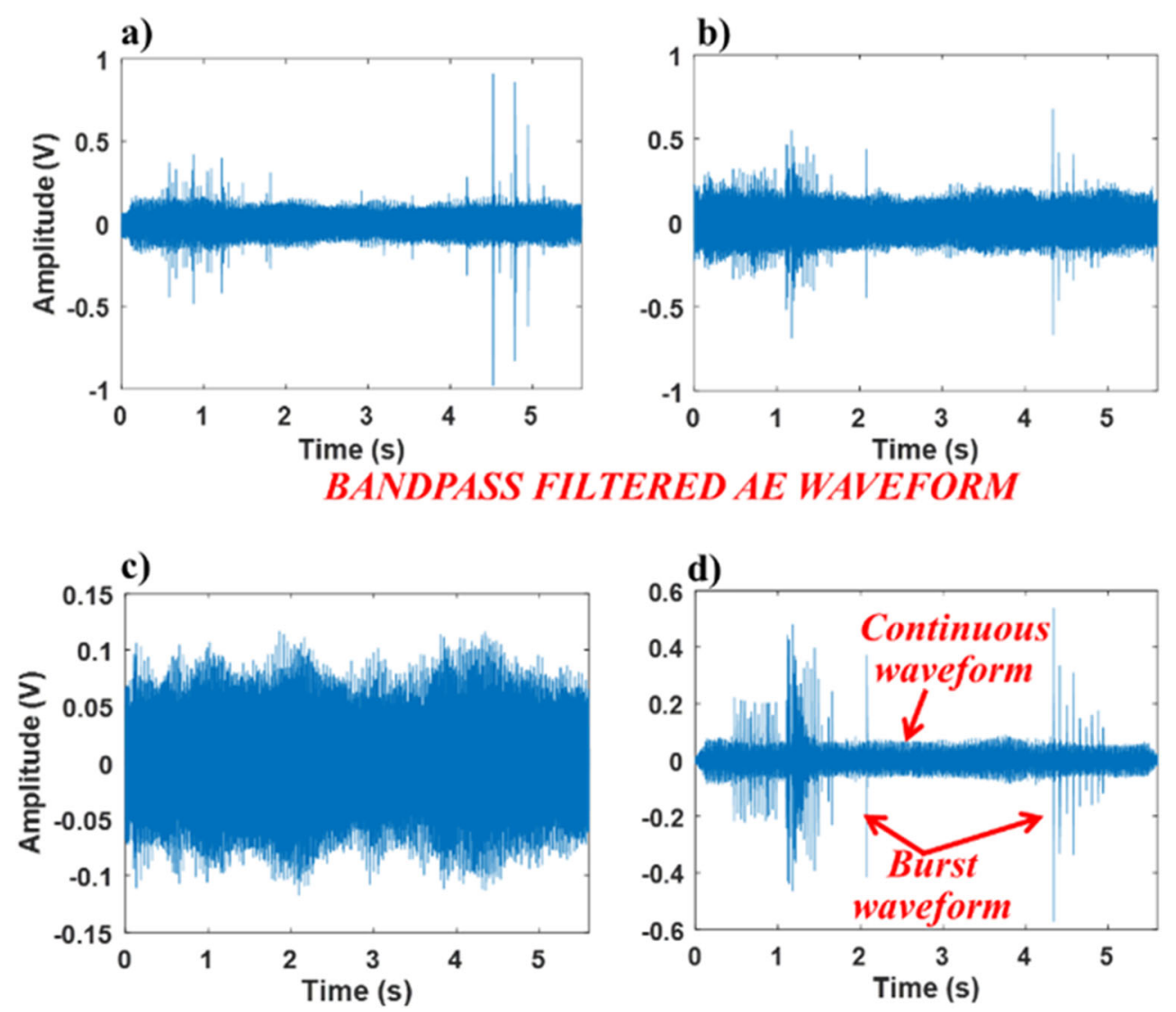

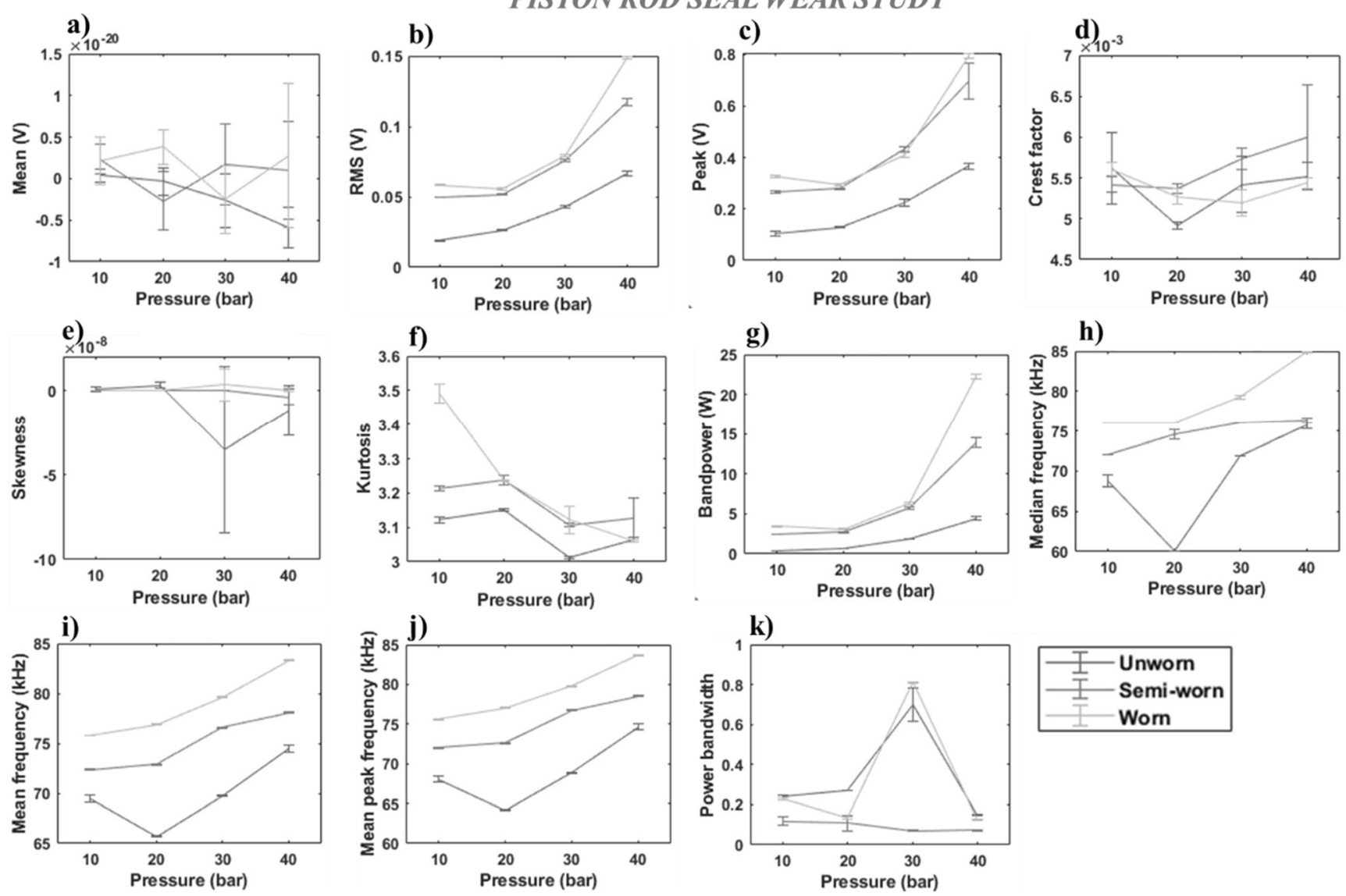

Fig. 8. Time-domain and frequency-domain features calculated from bandpass filtered $\mathrm{AE}$ waveform recorded from the piston rod seal wear test. $\boldsymbol{a}$ Mean; $\boldsymbol{b}$ RMS; $\boldsymbol{c}$ peak; $\boldsymbol{d}$ crest factor; $\boldsymbol{e}$ kurtosis; $\boldsymbol{f}$ skewness; $\boldsymbol{g}$

Whereas, in frequency-domain bandpower, median frequency, mean frequency and mean peak frequency can be used to understand non-leakage conditions due to unworn piston rod seal and leakage fluid conditions due to semi-worn or worn piston rod seal in the test rig (Fig. 8g)-j)). With the minimal standard deviation, AE features based on signal strength such as RMS, bandpower, median frequency, mean frequency, and mean peak frequency increase with an increase in wear condition of the piston rod seal, and have shown good capability in identifying and separating the features due to unworn, semiworn and worn piston rod seals at all the tested pressure conditions [22]. With an increase in pressure, an increase in $\mathrm{AE}$ features can be observed for RMS, peak, and bandpower for unworn, semi-worn and worn piston rod seal conditions, whereas for median-frequency, mean-frequency and meanpeak frequency the increase in AE features with an increase in pressure can be observed for semi-worn and worn seal conditions only. This increase in AE features with an increase in pressure is mainly due to a change in friction conditions at the piston rod seal interface [24].

To understand maximum separability percentage of the $\mathrm{AE}$ features between the piston rod seal wear conditions, separability percentage between the $\mathrm{AE}$ features is calculated for

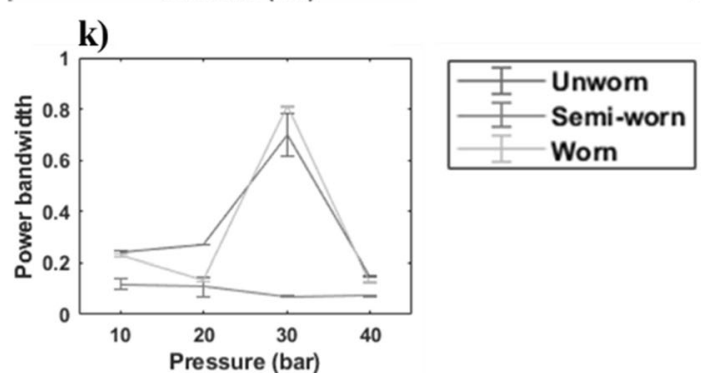

bandpower; $\boldsymbol{h}$ median frequency; $\boldsymbol{i}$ mean frequency; $\boldsymbol{j}$ mean peak frequency; $\boldsymbol{k}$ power bandwidth. (Note: Bandpass filtering range: $50-100 \mathrm{kHz}$ )

unworn vs semi-worn piston rod seal, and semi-worn vs. worn piston rod seal (Fig. 9). For unworn vs. semi-worn piston rod seal, maximum separability percentage is observed for the bandpower feature followed by peak, RMS, median frequency, mean frequency and mean peak frequency features (Fig. 9a)). Similarly, for semi-worn vs. worn piston rod seal, maximum separability percentage is observed for the bandpower feature followed by RMS, median frequency, mean frequency and mean peak frequency features (Fig. 9b)). The separability percentage for AE features is higher between unworn vs semiworn seal (Fig. 9a)) compared to that of separability percentage between semi-worn vs worn seal (Fig. 9b)).

\subsection{Analysis of AE waveform-bearing wear study}

\subsubsection{Bearing wear study with unworn piston rod seal}

Figure 10 represents the $\mathrm{AE}$ features calculated from the bandpass filtered $\mathrm{AE}$ waveform recorded from the bearing wear study performed using the unworn piston rod seal. In time-domain features RMS, peak and skewness can be used to identify unworn and worn bearings conditions in the test rig (Fig. 10b)-c), f)). In frequency-domain features, bandpower 
Fig. 9. Separability percentage of $\mathrm{AE}$ features calculated from bandpass filtered $\mathrm{AE}$ waveform $(50-100 \mathrm{kHz})$ from the seal study: $\boldsymbol{a}$ leakage (semi-worn seal) and non-leakage conditions (unworn seal); $\boldsymbol{b}$ leakage due to semi-worn and worn seal. (Note: In figure, each bar of AE feature is calculated by taking mean of separability (\%) from all four pressure conditions) a)

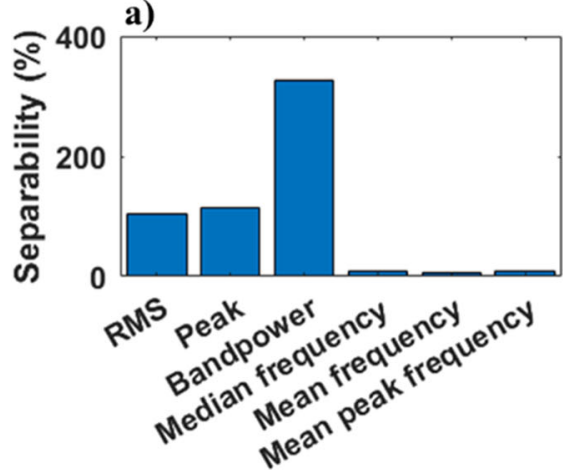

b)

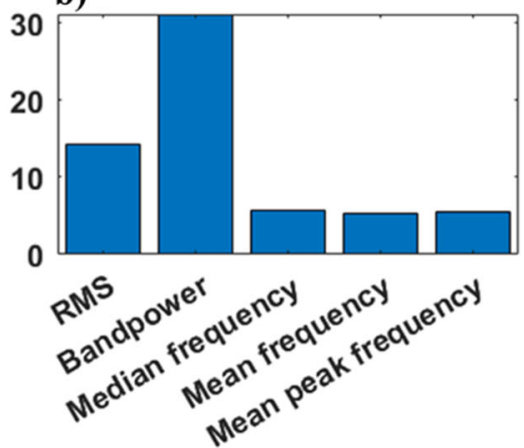

and median frequency can be used to identify unworn and worn bearing conditions in the test rig (Fig. 10g)-h)). RMS, peak, bandpower and median frequency show good repeatability in identifying unworn and worn bearings in the test rig at all pressure conditions. The AE feature value for RMS, peak, bandpower and median frequency has nearly similar values for 10 and 20 bar pressure conditions and a similar value for 30 and 40 bar pressure conditions. This is likely due to the increase in stress on bearings for the 30 and 40 bar pressure conditions. Major difference can be observed for the skewness feature between unworn and worn bearing conditions. For the worn bearing, skewness values are nearly zero at all pressures.

Figure 11 represents the separability percentage of $\mathrm{AE}$ features calculated between the bearing wear conditions from the experiments performed using the unworn piston

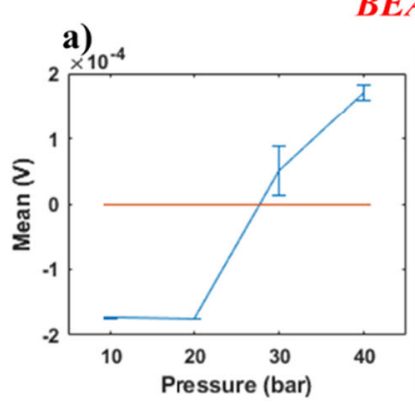

BEARING WEAR STUDY WITH UNWORN PISTON ROD SEAL
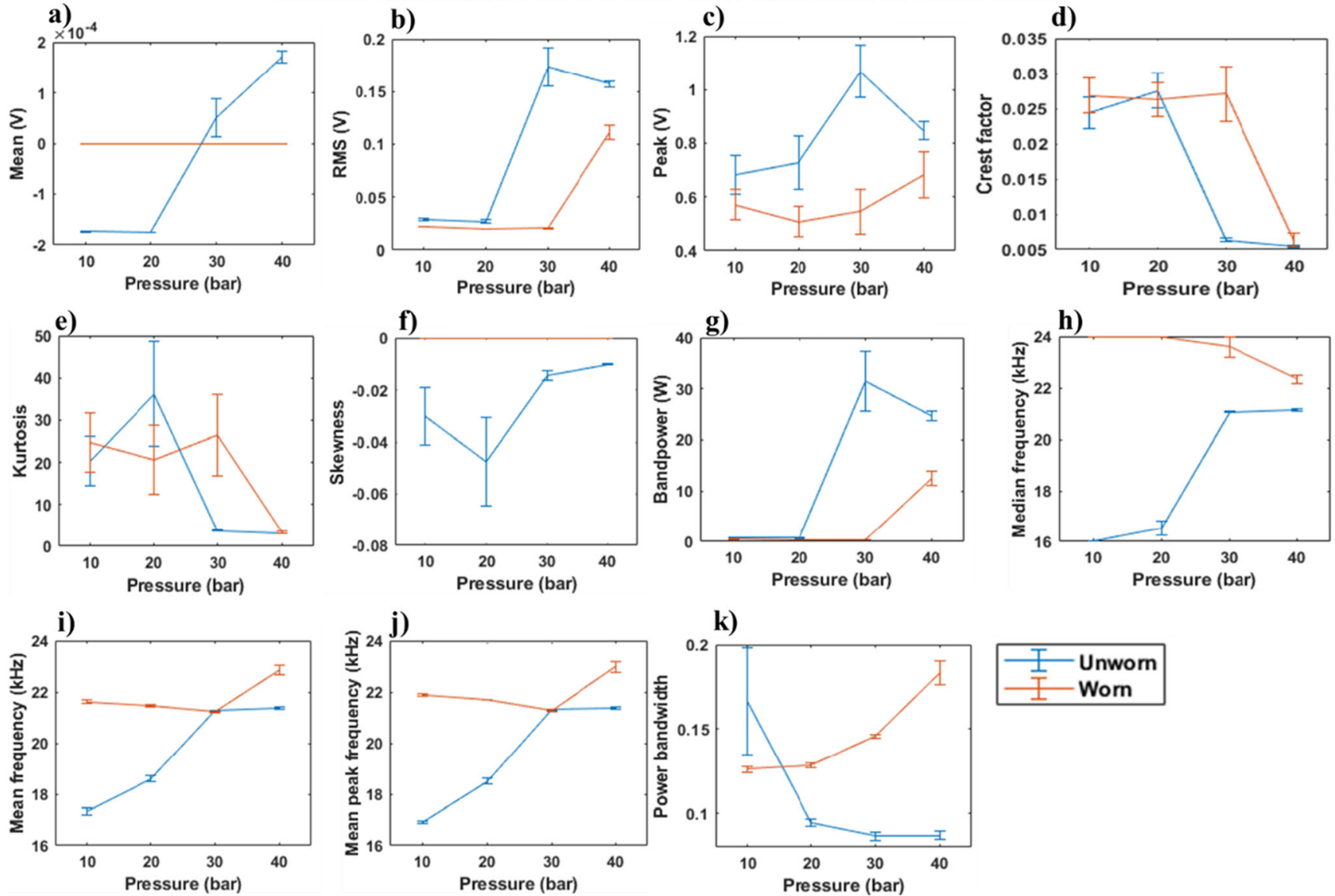

Fig. 10 Time-domain and frequency-domain features calculated from bandpass filtered $\mathrm{AE}$ waveform recorded from the bearing test performed using unworn seal. $\boldsymbol{a}$ Mean; $\boldsymbol{b}$ RMS; $\boldsymbol{c}$ peak; $\boldsymbol{d}$ crest factor; $\boldsymbol{e}$ kurtosis; $\boldsymbol{f}$ skewness; $\boldsymbol{g}$ bandpower; $\boldsymbol{h}$ median frequency; $\boldsymbol{i}$ mean frequency; $\boldsymbol{j}$ mean

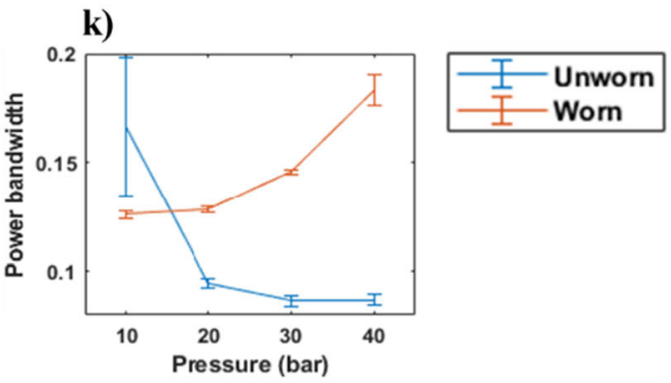

peak frequency; $\boldsymbol{k}$ power bandwidth. (Note: Bandpass filtering range: 15-30 kHz). (Note: In figure, each bar of AE feature is calculated by taking mean of separability (\%) from all four pressure conditions) 


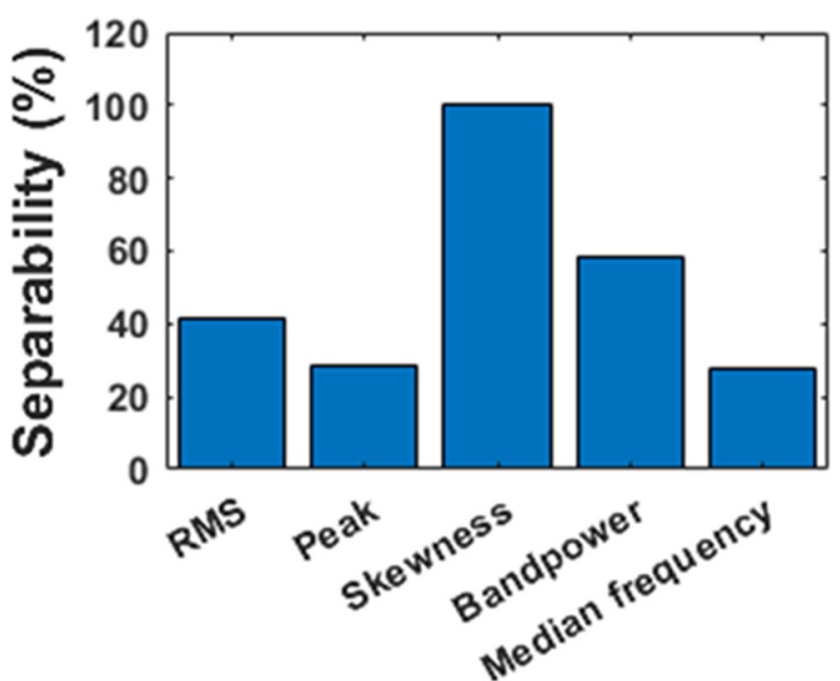

Fig. 11. Separability percentage of AE features calculated from bandpass filtered $(15-30 \mathrm{kHz}) \mathrm{AE}$ waveform from the bearing wear study using unworn piston rod seal. (Note: In figure, each bar of AE feature is calculated by taking mean of separability (\%) from all four pressure conditions) rod seal. Separability percentage is maximum for skewness followed by bandpower, RMS, peak and median frequency features. Separability percentage for skewness is 100 because the skewness value for worn seal is nearly zero at all pressures (Fig. 10f)).

\subsubsection{Bearing wear study with semi-worn piston rod seal}

Figure 12 represents the $\mathrm{AE}$ features calculated from the bandpass filtered $\mathrm{AE}$ waveform for the bearing wear study performed using the semi-worn piston rod seal. In timedomain features mean, peak and skewness can be used to understand unworn and worn bearings in the test rig (Fig. 12a), c), f)). A major difference can be observed for the $\mathrm{AE}$ feature values in mean and skewness between unworn and worn bearing conditions. This similar trend was also observed for the skewness feature in Fig. 10f). In frequency-domain features median frequency, mean peak frequency and power bandwidth can be used to understand unworn and worn bearings in the test rig (Fig. 12h), j), k)). In power bandwidth features, a linear increment can be observed for the unworn
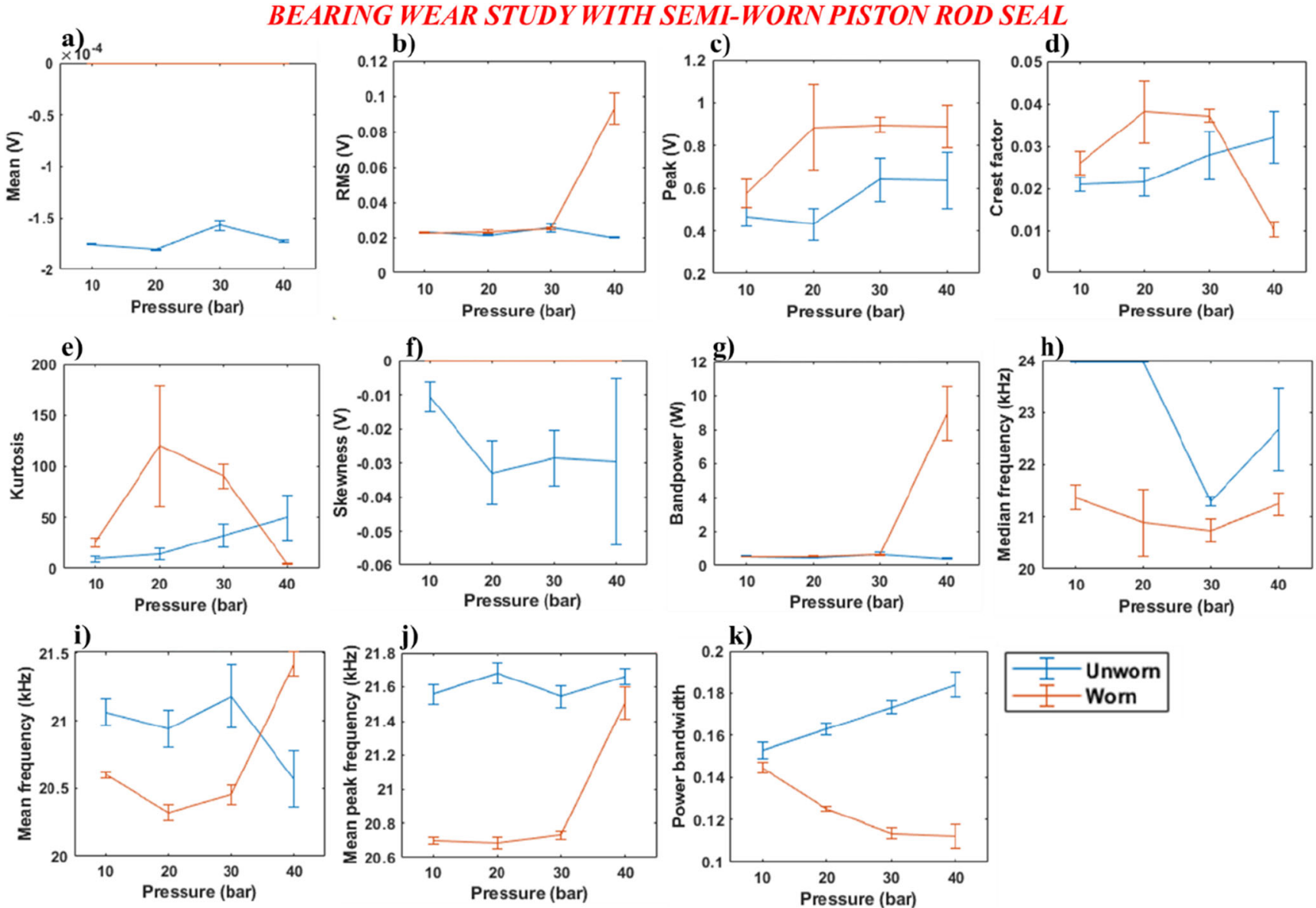

Fig. 12. Time-domain and frequency-domain features calculated from bandpass filtered $\mathrm{AE}$ waveform recorded from the bearing test performed using unworn seal. a Mean; b RMS; c peak; d crest factor; e kurtosis; $\mathbf{f}$

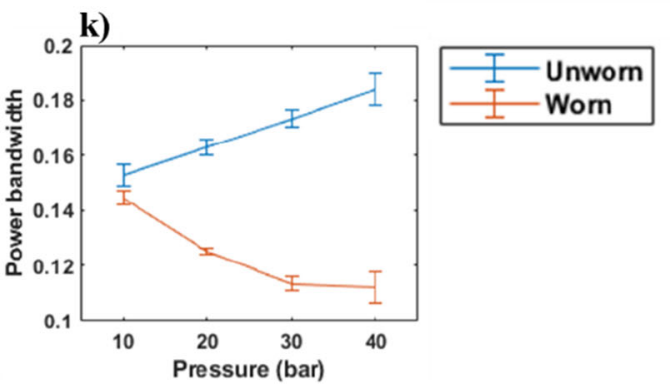

skewness; $\mathbf{g}$ bandpower; $\mathbf{h}$ median frequency; i mean peak frequency; $\mathbf{k}$ power bandwidth. (Note: Bandpass filtering range: $15-30 \mathrm{kHz}$ ) 


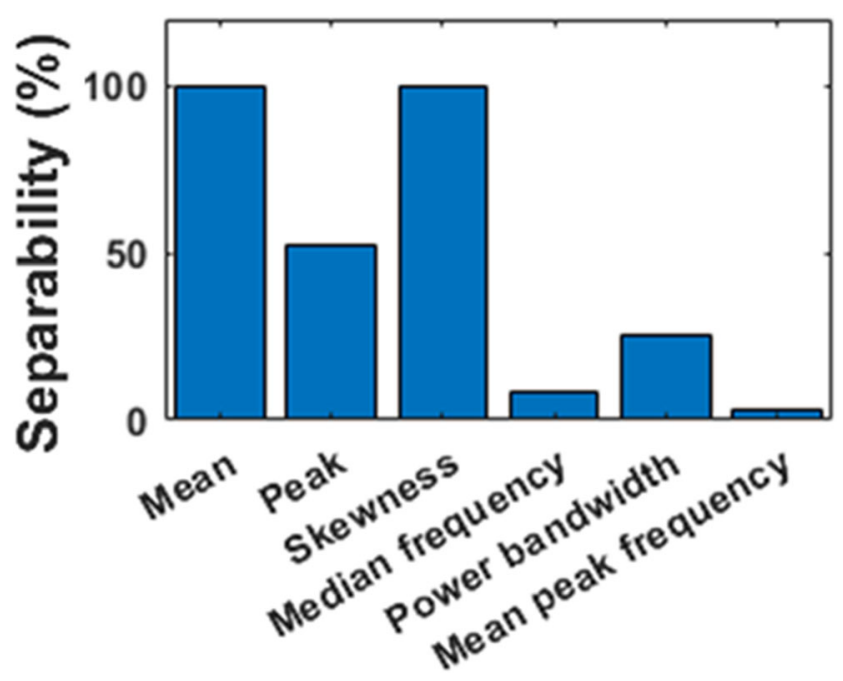

Fig. 13. Separability percentage of AE features calculated from bandpass filtered (15-30 kHz) AE waveform from the bearing wear study using semi-worn piston rod seal. (Note: In figure, each bar of AE feature is calculated by taking mean of separability $(\%)$ from all four pressure conditions)

bearings and decrement trend can be observed for the worn bearings with increase in pressure conditions. This indicates that the resonant components observed for the worn bearings is of low power which has resulted in reduction of power bandwidth $[39,40]$.

Figure 13 represents the separability percentage of AE features calculated between the bearing wear conditions from the experiments performed using semi-worn piston rod seal. Separability percentage is maximum for mean and skewness followed by peak, power bandwidth, median frequency and mean peak frequency features. There are at least two features with separability percentage of 100 (mean and skewness). The time-domain features mean, peak and skewness have higher separability percentage compared to frequency-domain features such as median frequency, power bandwidth and mean peak frequency.

\subsubsection{Bearing wear study with a worn piston rod seal}

Figure 14 represents AE features calculated from the bandpass filtered $\mathrm{AE}$ waveform from the bearing wear study performed using the worn piston rod seal. In time-domain features mean and RMS can be used to identify unworn and worn bearing conditions in the test rig (Fig. 14a)-b)). In frequency-domain

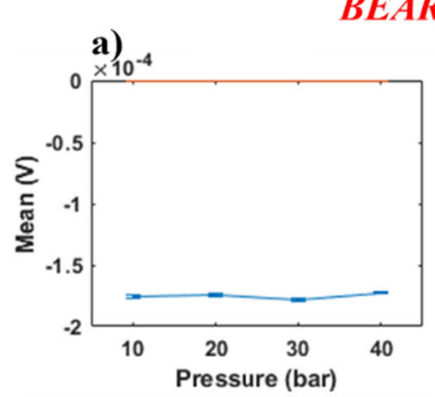

BEARING WEAR STUDY WITH WORN PISTON ROD SEAL
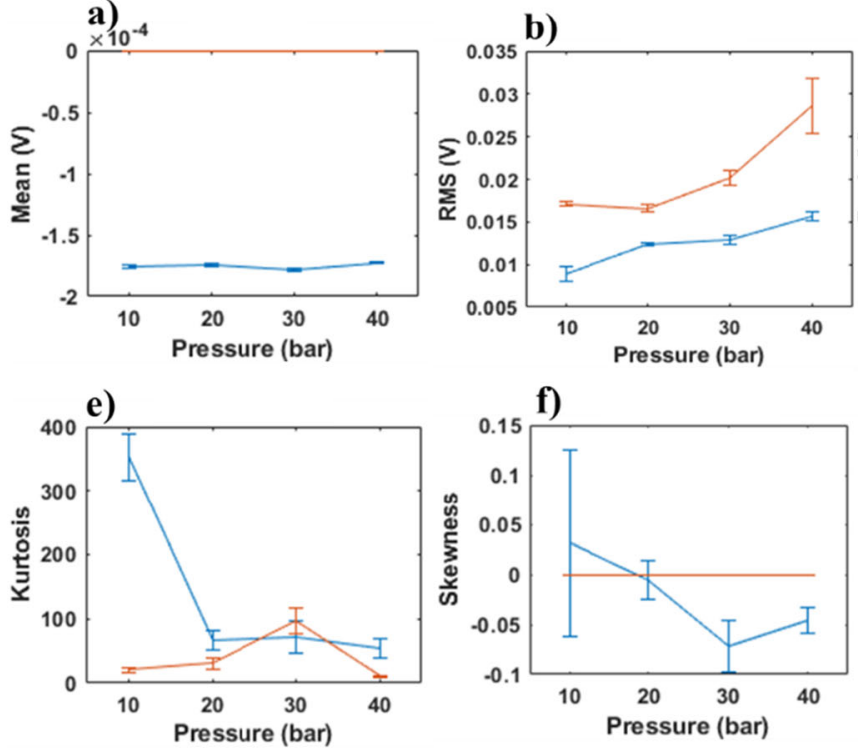

c)
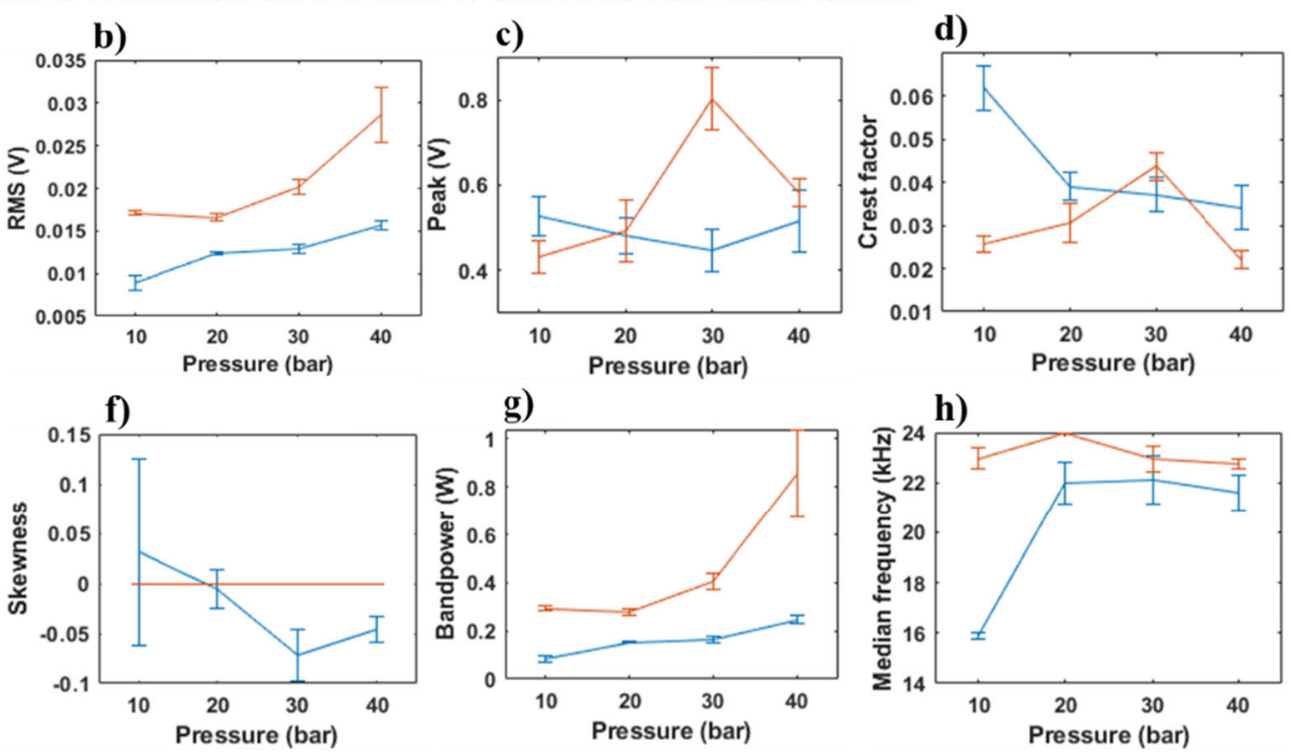

h)
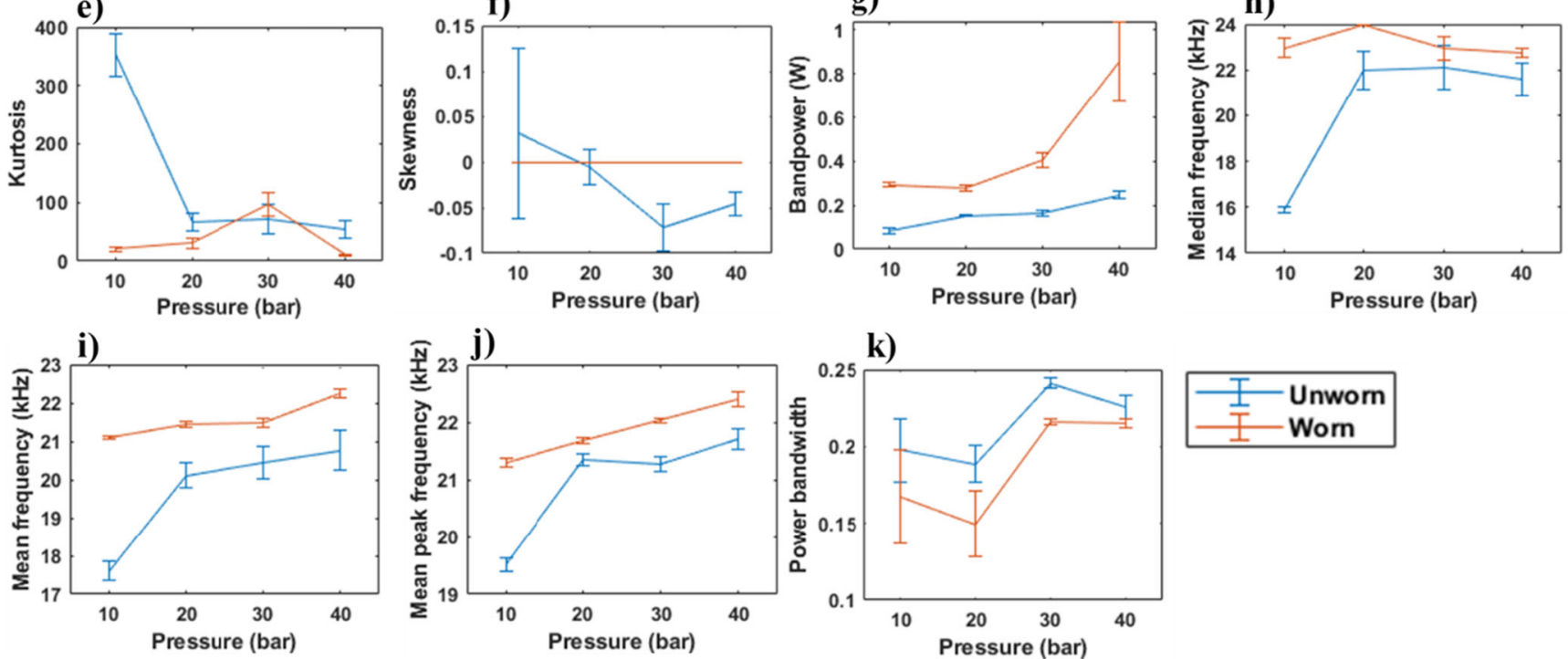

Fig. 14. Time-domain and frequency-domain features calculated from bandpass filtered $\mathrm{AE}$ waveform recorded from the bearing test performed using unworn seal. a Mean; b RMS; c peak; d crest factor; e kurtosis; f
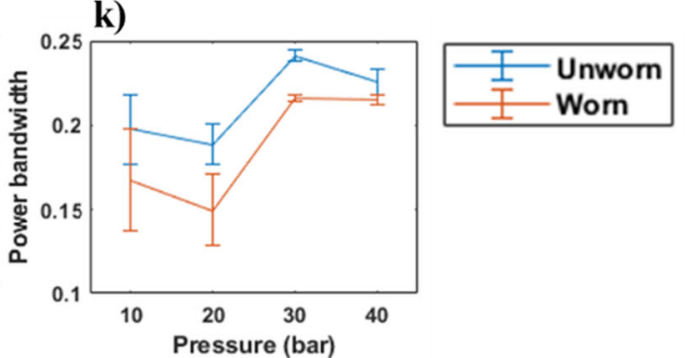

skewness; $\mathbf{g}$ bandpower; $\mathbf{h}$ median frequency; i mean peak frequency; $\mathbf{k}$ power bandwidth. (Note: Bandpass filtering range: $15-30 \mathrm{kHz}$ ) 
features bandpower, median frequency, mean frequency, mean peak frequency and power bandwidth can be used to identify unworn and worn bearing conditions in the test rig (Fig. 14g)-k)). In RMS, bandpower, mean frequency and mean peak frequency an increment in values can be observed with an increase in pressure for unworn and worn bearing conditions. For the worn bearing condition, the mean and skewness values are zero at all the pressure conditions (Fig. 14a), f)). This trend was also observed in the bearing wear study performed using unworn and worn piston rod seals (Fig. 10a), f), Fig. 12a), f)). Skewness value of nearly zero indicates that, the $\mathrm{AE}$ waveform data is nearly symmetrical [41].

Figure 15 represents the separability percentage of AE features calculated from the bearing wear conditions from the experiments performed using a worn piston rod seal. The separability percentage is maximum for bandpower feature followed by mean, RMS, peak, median frequency, power bandwidth, mean frequency and mean peak frequency. There are at least two AE features with percentage separability of more than $100 \%$ (mean and bandpower). The separability percentage for the mean feature is 100 because the value for the worn bearing is nearly zero for all the pressure (Fig. 14a)). Similarly, the separability percentage for the bandpower feature is nearly 150 because the feature value for the worn bearing at 40 bar is at least seven times more than that of the unworn bearing.

\subsection{Analysis of AE waveform-run-to-failure test}

The AE features were extracted from approximately 63,000 burst waveforms and were plotted against time. In AE time-

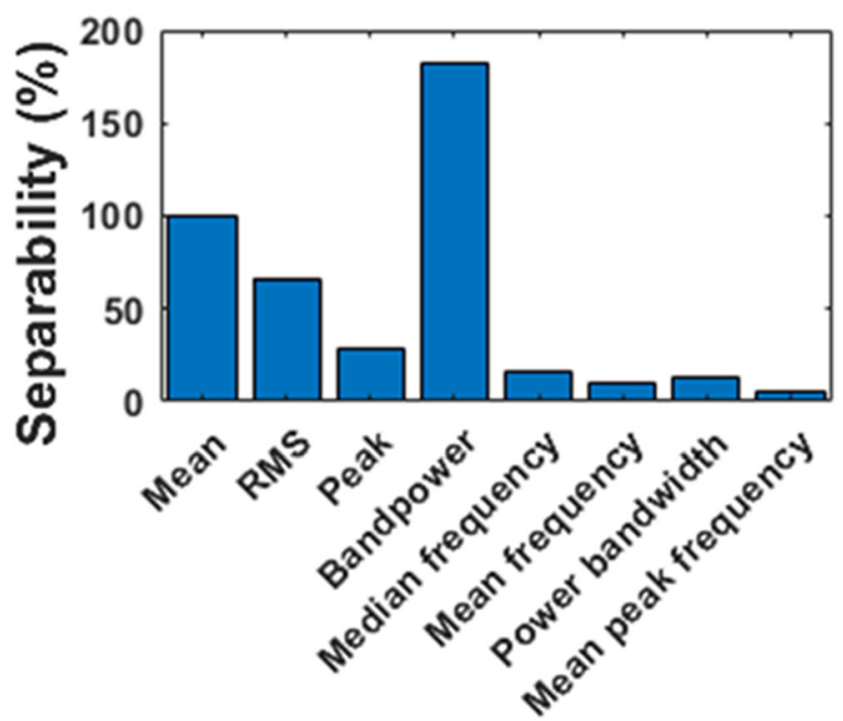

Fig. 15 Separability percentage of AE features calculated from bandpass filtered $(15-30 \mathrm{kHz}) \mathrm{AE}$ waveform from the bearing wear study using worn piston rod seal. (Note: In figure, each bar of AE feature is calculated by taking mean of separability (\%) from all four pressure conditions) domain and frequency-domain features, a minor change in trend can be observed in RMS, skewness, bandpower and power bandwidth after $12.6 \mathrm{~h}$ (Fig. 16b), f), g), k)). Whereas, features such as median frequency, mean frequency and mean peak frequency showed a clear indication of fluid leakage initiation in the test rig (Fig. 16h)-j)), confirming the analysis of continuous waveform performed in the two first phases of this study. From Fig. 16h)-j), during the nonleakage condition, the $\mathrm{AE}$ frequency range is between 70 and $80 \mathrm{kHz}$. When the fluid leakage initiates, the AE frequency range increases to $73-90 \mathrm{kHz}$ (Fig. 16h)-j)). Figure 161) represents the fluid leakage on the piston rod when the test was stopped after $17 \mathrm{~h}$. The fluid leakage observed on the piston rod is still very small when compared to the fluid leakage that was observed with the completely worn piston rod seal in the test rig (Fig. 1d)). Therefore, in this study, the median frequency, mean frequency and mean peak frequency features have shown good capability to identify piston rod seal wear at very initial stages during the run-to-failure tests.

\section{Discussion}

In this study, eleven $\mathrm{AE}$ features were calculated from bandpass filtered $\mathrm{AE}$ waveform to understand piston rod seal and bearing wear in the hydraulic test rig. In Table 5, a summary of AE features that can be used to understand piston rod seal and bearing wear is presented. To understand non-leakage and fluid leakage conditions in the test rig, six AE features were identified. Whereas, to understand different seal wear conditions such as unworn, semi-worn and worn seal conditions, five $\mathrm{AE}$ features were identified. To understand bearing wear conditions in test rig using unworn seal, five AE features were identified. To identify bearing wear conditions in test rig using semi-worn seal, six AE features were identified. To identify bearing wear conditions in test rig using worn piston rod seal, seven AE features were identified. To identify fluid leakage initiation due to wear of piston rod seal, seven $\mathrm{AE}$ features were identified. Results found in literature on identifying fluid leakage using AE, Chen et al. [22], proposed energy-based features such as AE RMS to identify fluid leakage conditions. Shanbhag et al. $[24,25]$ proposed combination of AE features such as bandpower, mean frequency, and median frequency to identify piston rod seal wear. However, in literature, the $\mathrm{AE}$ features that can identify multiple component failures in hydraulic cylinders based on frequency band is not clear. In this study, AE features that can identify component failures based on frequency band is studied and proposed. In Table 5, the median frequency feature calculated based on component frequency band has shown good repeatability and separability in identifying piston rod seal wear and bearing wear at all the pressure conditions. Based on the repeatability observed for median frequency feature in Table 5 , the median 

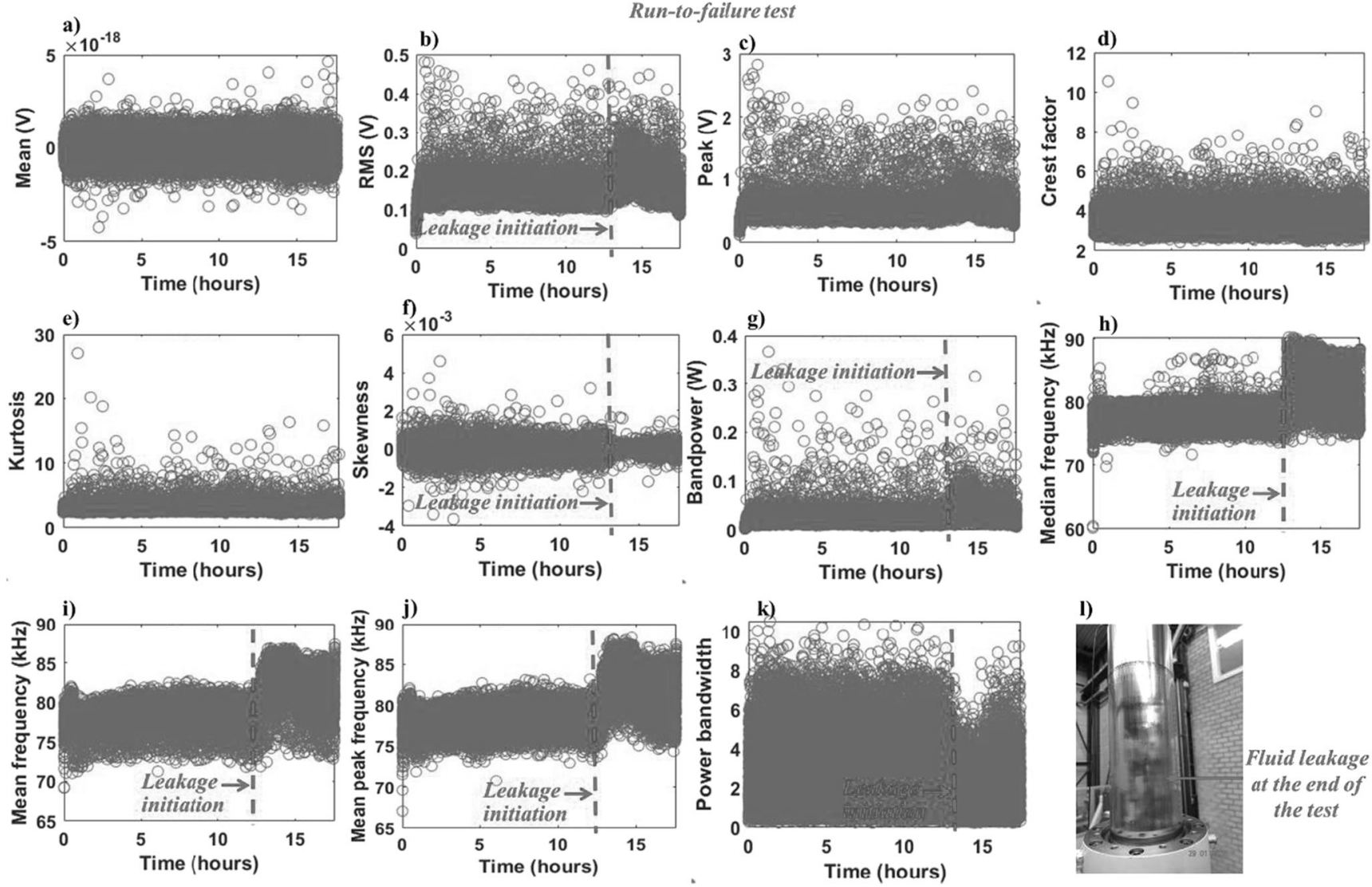

Fig. 16 AE features extracted from run-to-failure tests $\boldsymbol{a}$ mean; $\boldsymbol{b}$ RMS; $\boldsymbol{c}$ peak; $\boldsymbol{d}$ crest factor; $\boldsymbol{e}$ kurtosis; $\boldsymbol{f}$ skewness; $\boldsymbol{g}$ bandpower; $\boldsymbol{h}$ median on piston rod surface at the end of run-to-failure test. (Note: Bandpass filter band used for AE burst waveform: $50-100 \mathrm{kHz}$ )

Table 5 Summary of AE features for piston rod seal and bearing wear identification

\begin{tabular}{|c|c|c|c|c|c|c|}
\hline \multirow[t]{2}{*}{ Features } & \multicolumn{2}{|c|}{$\begin{array}{l}\text { Piston rod seal study }(50-100 \\
\mathrm{kHz})\end{array}$} & \multicolumn{3}{|c|}{ Bearing wear study $(15-30 \mathrm{kHz})$} & \multirow[t]{2}{*}{$\begin{array}{l}\text { Run-to-failure test (50- } \\
100 \mathrm{kHz})\end{array}$} \\
\hline & $\begin{array}{l}\text { Unworn vs } \\
\text { semi-worn }\end{array}$ & $\begin{array}{l}\text { Semi-worn vs. } \\
\text { worn }\end{array}$ & $\begin{array}{l}\text { Unworn piston } \\
\text { rod seal }\end{array}$ & $\begin{array}{l}\text { Semi-worn piston } \\
\text { rod seal }\end{array}$ & $\begin{array}{l}\text { Worn piston } \\
\text { rod seal }\end{array}$ & \\
\hline Mean & $\mathrm{N}$ & $\mathrm{N}$ & $\mathrm{N}$ & $\mathrm{Y}$ & $\mathrm{Y}$ & $\mathrm{N}$ \\
\hline RMS & $\mathrm{Y}$ & $\mathrm{Y}$ & $\mathrm{Y}$ & $\mathrm{N}$ & $\mathrm{Y}$ & $\mathrm{Y}$ \\
\hline Peak & $\mathrm{Y}$ & $\mathrm{N}$ & $\mathrm{Y}$ & $\mathrm{Y}$ & $\mathrm{N}$ & $\mathrm{N}$ \\
\hline Skewness & $\mathrm{N}$ & $\mathrm{N}$ & Y & $\mathrm{Y}$ & $\mathrm{N}$ & $\mathrm{Y}$ \\
\hline Kurtosis & $\mathrm{N}$ & $\mathrm{N}$ & $\mathrm{N}$ & $\mathrm{N}$ & $\mathrm{N}$ & $\mathrm{N}$ \\
\hline Crest factor & $\mathrm{N}$ & $\mathrm{N}$ & $\mathrm{N}$ & $\mathrm{N}$ & $\mathrm{N}$ & $\mathrm{N}$ \\
\hline Bandpower & $\mathrm{Y}$ & $\mathrm{Y}$ & Y & $\mathrm{N}$ & $\mathrm{Y}$ & $\mathrm{Y}$ \\
\hline Median frequency & $\mathrm{Y}^{*}$ & $\mathrm{Y}^{*}$ & $\mathrm{Y}^{*}$ & $\mathrm{Y}^{*}$ & $\mathrm{Y}^{*}$ & $\mathrm{Y}^{*}$ \\
\hline Mean frequency & Y & $\mathrm{Y}$ & $\mathrm{N}$ & $\mathrm{N}$ & Y & $\mathrm{Y}$ \\
\hline Power bandwidth & $\mathrm{N}$ & $\mathrm{N}$ & $\mathrm{N}$ & $\mathrm{Y}$ & $\mathrm{Y}$ & $\mathrm{Y}$ \\
\hline Mean peak frequency & $\mathrm{Y}$ & $\mathrm{Y}$ & $\mathrm{N}$ & $\mathrm{Y}$ & $\mathrm{Y}$ & $\mathrm{Y}$ \\
\hline $\begin{array}{l}\text { No of features for condition } \\
\text { monitoring }\end{array}$ & 6 & 5 & 5 & 6 & 7 & 7 \\
\hline
\end{tabular}

$Y$, can be used as condition monitoring indicator; $N$, cannot be used as condition monitoring indicator; $Y^{*}$, consistency in identifying wear conditions for piston rod seal and bearings 
a)

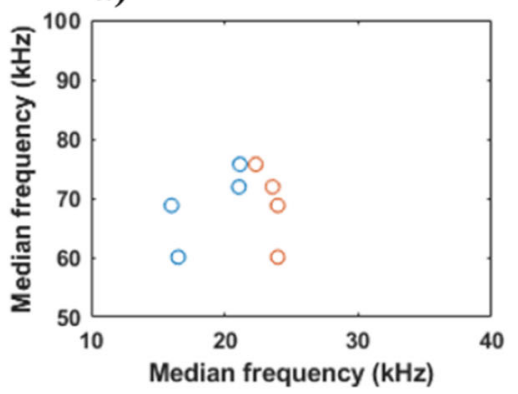

Fig. 17. Correlation of unworn and worn bearings $(15-30 \mathrm{kHz})$ with the different piston rod seal conditions (50-100 kHz) with $\boldsymbol{a}$ unworn seal; $\boldsymbol{b}$ semi-worn seal; $\boldsymbol{c}$ worn seal. (Note: $X$-axis represents median frequency

frequency feature is further used to understand correlation between piston rod seal wear and bearing wear.

Figure 17 represents the correlation for the median frequency feature calculated for unworn and worn bearings with the different piston rod seal wear conditions. With unworn piston rod seal, unworn and worn bearings, the median frequency is dominant between 60 and $75 \mathrm{kHz}$ (Fig. 17a)). Similarly, with semi-worn piston rod seal, unworn and worn bearings, the median frequency is dominant between 70 and $80 \mathrm{kHz}$ (Fig. 17b)). With worn piston rod seal, unworn and worn bearings, the median frequency is dominant between 75 and $90 \mathrm{kHz}$ (Fig. 17c)). Therefore, with an increase in piston rod seal wear conditions, the median frequency value increases irrespective of unworn or worn bearing conditions. From Figs. 10h), 12h), 14h), and 17a)-c), the AE information related to bearing wear, is dominant in frequency range of 15-25 kHz. In Fig. 17a), c), the AE frequency range is higher for worn bearings compared to unworn bearings. In Fig. 17b)-c), the AE frequency range for unworn bearings is nearly same $(\approx 21 \mathrm{kHz}$ average $)$. The AE frequency range is higher for unworn bearings compared to the worn bearings in Fig. 17b). This may be due to a number of factors such as presence of high number of resonant frequency components in the lower frequency range for the worn bearings or due to variation of stress conditions on the worn bearings (Fig. 12h)) [24, 42]. However, irrespective of piston rod seal wear, the change in bearing wear conditions can be identified (Table 5).

Compared to the literature of the work done on monitoring fluid leakage due to seal wear in hydraulic cylinders using $\mathrm{AE}$ $[4,22,24]$, in this study, an attempt was made to identify (a) seal wear conditions (b) bearing wear under non-leakage and leakage conditions, and (c) initial stages of fluid leakage initiation due to seal wear in the test rig. The $\mathrm{AE}$ features were identified based on the frequency band of the component in the test rig. From Table 5, median frequency AE feature has shown good repeatability in identifying piston rod seal wear and bearing wear at all the pressure conditions, and it can be also be used further to identify initial stages of fluid leakage due c)

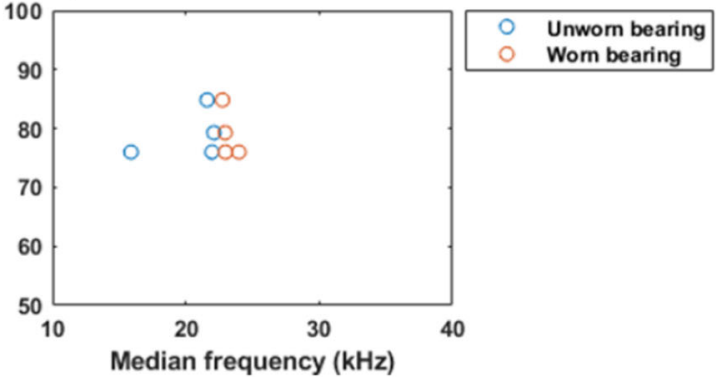

feature calculated from phase two (bearing wear study) and Y-axis represents median frequency feature calculated from phase one (seal wear study))

to seal wear in the test rig (Fig. 16). The proposed condition monitoring methodology in this study, identifies $\mathrm{AE}$ features based on particular frequency bands associated to specific components in the test rig, making it less susceptible to noise from other components. Therefore, this work can be adapted in the industries for continuous monitoring of hydraulic cylinders by using stud-based AE sensors on large hydraulic cylinders or by mounting it on the clevis part of small hydraulic cylinders.

\section{Conclusion}

This study presented a robust acoustic emission-based condition monitoring technique that can be used in industries to monitor multiple faults in hydraulic cylinders at the same time. In this study, piston rod seal wear identification and bearing wear identification under different seal conditions were studied using AE. The main findings from this study are as follows:

- For the system tested, the AE frequency band of piston rod seal is in frequency band of $50-100 \mathrm{kHz}$ and for bearings is in frequency band of $15-30 \mathrm{kHz}$.

- AE RMS, bandpower, median frequency, mean frequency and power bandwidth calculated from the bandpass filtered $\mathrm{AE}$ waveform can be used to monitor non-leakage conditions due to unworn piston rod seal, and leakage conditions due to semi-worn and worn piston rod seal in the test rig.

- AE peak, skewness and median frequency from the bandpass filtered $\mathrm{AE}$ waveform can be used to monitor bearing wear irrespective of non-leakage or fluid leakage conditions in hydraulic test rig.

- AE median frequency feature calculated from the bandpass filtered $\mathrm{AE}$ waveform can be used as condition monitoring indicator as it has shown good repeatability in identifying seal wear and bearing wear at different pressure conditions. 
- In the correlation study of the AE median frequency feature between the unworn and worn bearings $(15-30 \mathrm{kHz})$ versus different seal conditions $(50-100 \mathrm{kHz})$, the median frequency increases with increase in piston rod seal wear irrespective of unworn or worn bearings in test rigs.

- Using median frequency, mean frequency and mean peak frequency feature from the bandpass filtered $\mathrm{AE}$ burst waveform, it was possible to understand the fluid leakage initiation point due to piston rod seal wear.

The AE-based condition monitoring technique based on bandpass filtering presented in this study can be used in industries as AE features has shown good sensitivity and reliability for different pressure conditions, piston rod seal wear conditions and bearing wear conditions.

Data and materials availability The authors confirm that, data supporting the findings will be made available upon request.

Code availability The authors confirm that, MATLAB code supporting the findings will be made available upon request.

Authors' contributions Vignesh. V. Shanbhag: Developing experimental methodology, data processing and analysis, writing-review, and editing article. Thomas J. J. Meyer: Project administration, reviewing article. Leo. W. Caspers: Inputs for experimental methodology, providing lab facilities at Bosch Rexroth, review and editing article.. Rune Schlanbusch: Inputs for data processing and analysis, review and editing article.

Funding Open access funding provided by NORCE Norwegian Research Centre AS. The research presented in this paper has received funding from the Norwegian Research Council, SFI Offshore Mechatronics, project number 237896.

\section{Declarations}

Consent to publish Authors declare that upon acceptance of the article, authors agree to publish the article in open access under the agreement between Springer and Norwegian Research Centre AS.

Conflict of interest The authors declare that they have no conflict of interest.

Open Access This article is licensed under a Creative Commons Attribution 4.0 International License, which permits use, sharing, adaptation, distribution and reproduction in any medium or format, as long as you give appropriate credit to the original author(s) and the source, provide a link to the Creative Commons licence, and indicate if changes were made. The images or other third party material in this article are included in the article's Creative Commons licence, unless indicated otherwise in a credit line to the material. If material is not included in the article's Creative Commons licence and your intended use is not permitted by statutory regulation or exceeds the permitted use, you will need to obtain permission directly from the copyright holder. To view a copy of this licence, visit http://creativecommons.org/licenses/by/4.0/.

\section{References}

1. ISO 5597:2018. Hydraulic fluid power - cylinders — dimensions and tolerances of housings for single-acting piston and rod seals in reciprocating applications [Internet]. Available from: https://www. iso.org/standard/74704.html. Accessed 3 Jul 2020

2. Gonzalo A. Barillas, Steven Cowell, Martin Goerres, Wolfgang Lipphardt, Uwe Siegrist SM. Sealing systems for hydraulic cylinders. 11th International Fluid Power Conference [Internet]. 2018. p. 283-93. Available from: http://publications.rwth-aachen.de/record/ 726053/files/726053.pdf. Accessed 14 May 2020

3. Goharrizi AY, Sepehri N (2011) A wavelet-based approach for external leakage detection and isolation from internal leakage in valve-controlled hydraulic actuators. IEEE Trans Ind Electron 58: 4374-4384

4. Shanbhag VV, Meyer TJJ, Caspers LW, Schlanbusch R (2021) Failure monitoring and predictive maintenance of hydraulic cylinder - a state of art review. IEEE/ASME Trans Mechatron:1. https:// doi.org/10.1109/TMECH.2021.3053173

5. Lloyd L. Hydraulic system leakage - The destructive drip [Internet]. Machinery Lubrication. 2000 [cited 2020 May 22]. Available from: https://www.machinerylubrication.com/Read/21/hydraulic-systemleakage. Accessed 22 May 2020

6. Sun X, Wang X, Lin S (2020) Multi-fault diagnosis approach based on updated interacting multiple model for aviation hydraulic actuator. Information 11(9):410

7. An L, Sepehri N (2005) Hydraulic actuator leakage fault detection using extended Kalman filter. Int J Fluid Power 6(1):41-51

8. Goharrizi AY, Sepehri N, Wu Y (2010) A wavelet-based approach for diagnosis of internal leakage in hydraulic actuators using on-line measurements. Int J Fluid Power 11(1):61-69

9. Goharrizi AY, Sepehri N (2012) Internal leakage detection in hydraulic actuators using empirical mode decomposition and hilbert spectrum. IEEE Trans Instrum Meas 61:368-378

10. Zhao X, Zhang S, Zhou C, Hu Z, Li R, Jiang J (2015) Experimental study of hydraulic cylinder leakage and fault feature extraction based on wavelet packet analysis. Comput Fluids 106:33-40

11. Tang H, Wu Y, Ma C (2010) Inner leakage fault diagnosis of hydraulic cylinder using wavelet energy. Adv Mater Res 139: 2517-2521

12. Jin Y, Shan C, Wu Y, Xia Y, Zhang Y, Zeng L (2018) Fault diagnosis of hydraulic seal wear and internal leakage using wavelets and wavelet neural network. IEEE Trans Instrum Meas 68(4): 1026-1034

13. Zhao X, Wang J (2019) Pump-back effect analysis and wear feature extraction for hydraulic cylinder piston seal based on multisensor monitoring. IEEE Trans Ind Electron

14. Tan ACH, Chua PSK, Lim GH (2003) Fault diagnosis of water hydraulic actuators under some simulated faults. J Mater Process Technol 138(1-3):123-130

15. Tan ACH, Chua PSK, Lim GH (2000) Condition monitoring of a water hydraulic cylinder by vibration analysis. Journal of testing and evaluation. ASTM Int 28:507-512

16. Yunbo H, Lim G, Chua P, Tan A (2001) Monitoring the condition of loaded modern water hydraulic axial piston motor and cylinder. Proceedings of the Fifth International Conference on Fluid Power Transmission and Control, p 447-51

17. Ramachandran M, Siddique Z (2019) A data-driven, statistical feature-based, neural network method for rotary seal prognostics. J Nondestruct Eval Diagn Prog Eng Syst 2(2)

18. Ramachandran M, Siddique Z (2018) Statistical time domain feature based approach to assess the performance degradation of rotary seals. ASME International Mechanical Engineering Congress and Exposition, Proceedings (IMECE) 
19. Boness RJ, McBride SL, Sobczyk M (1990) Wear studies using acoustic emission techniques. Tribol Int 23(5):291-295

20. Jiaa CL, Dornfeld DA (1990) Experimental studies of sliding friction and wear via acoustic emission signal analysis. Wear 139(2): 403-424

21. Hase A, Wada M, Mishina H (2008) The relationship between acoustic emissions and wear particles for repeated dry rubbing. Wear 265(5-6):831-839

22. Chen P, Chua PSK, Lim GH (2007) A study of hydraulic seal integrity. Mech Syst Signal Process 21(2):1115-1126

23. Petersen D, Link R, Chen P, Chua P, Lim G (2005) An experimental study of monitoring internal leakage in water hydraulic cylinders using acoustic emission. J Test Eval 33(6):445-451

24. Shanbhag VV, Meyer TJJJ, Caspers LW, Schlanbusch R (2020) Condition monitoring of hydraulic cylinder seals using acoustic emissions. Int J Adv Manuf Technol 109(5):1727-1739

25. Shanbhag VV, Meyer T, Caspers L, Schlanbusch R (2020) Acoustic emission based condition monitoring study of piston rod seals by varying speed and pressure parameters. Annual Conference of the PHM Society, $\mathrm{p} 9$

26. Zhang P, Chen X (2021) Internal leakage diagnosis of a hydraulic cylinder based on optimization DBN using the CEEMDAN technique. Shock Vib 2021

27. Towsyfyan H, Gu F, Ball AD, Liang B (2019) Tribological behaviour diagnostic and fault detection of mechanical seals based on acoustic emission measurements. Friction 7(6):572-586.

28. Ibarra-Zarate D, Tamayo-Pazos O, Vallejo-Guevara A (2019) Bearing fault diagnosis in rotating machinery based on cepstrum pre-whitening of vibration and acoustic emission. Int J Adv Manuf Technol 104(9):4155-4168

29. Sun S, Hu X, Zhang W (2020) Detection of tool breakage during milling process through acoustic emission. Int J Adv Manuf Technol 109(5):1409-1418

30. Gonzalez C (2017) 7 common failures of hydraulic seals. Mach Des 2017. Date accessed: July-10-2020

31. R15 $\alpha$ Sensor (General purpose sensor) [Internet]. [cited 2021 Apr 19]. Available from: http://www.physicalacoustics.com/ content/literature/sensors/Model_R15a.pdf. Accessed 19 Apr 2021

32. Binsaeid S, Asfour S, Cho S, Onar A (2009) Machine ensemble approach for simultaneous detection of transient and gradual abnormalities in end milling using multisensor fusion. J Mater Process Technol 209(10):4728-4738
33. Lei Y, He Z, Zi Y, Chen X (2008) New clustering algorithm-based fault diagnosis using compensation distance evaluation technique. Mech Syst Signal Process 22(2):419-435

34. Phinyomark A, Thongpanja S, Hu H, Phukpattaranont P, Limsakul C (2012) The usefulness of mean and median frequencies in electromyography analysis. Computational Intelligence in Electromyography Analysis - A Perspective on Current Applications and Future Challenges pp. 195-220

35. Mean Peak Frequency [Internet]. [cited 2020 Nov 13]. Available from: https://www.mathworks.com/help/predmaint/ $/ \mathrm{g} /$ conditionmonitoring-and-prognostics-using-vibration-signals.html. Accessed 13 Nov 2020

36. Central Tendency and Dispersion [Internet]. [cited 2020 Nov 13]. Available from: https://nl.mathworks.com/help/stats/descriptivestatistics.html?s_tid=CRUX_lftnav. Accessed 13 Nov 2020

37. Allahyari HM, Nikbin I, Rahimi RS, Allahyari A (2018) Experimental measurement of dynamic properties of composite slabs from frequency response. Meas J Int Meas Confed 114:150161

38. Sun J, Wood RJK, Wang L, Care I, Powrie HEG (2005) Wear monitoring of bearing steel using electrostatic and acoustic emission techniques. Wear 259(7-12):1482-1489

39. Lacidogna G, Piana G, Carpinteri A (2019) Damage monitoring of three-point bending concrete specimens by acoustic emission and resonant frequency analysis. Eng Fract Mech 210:203-211

40. Bassiuny AM, Li X, Du R (2007) Fault diagnosis of stamping process based on empirical mode decomposition and learning vector quantization. Int J Mach Tools Manuf 47(15):2298-2306

41. Caesarendra W, Kosasih B, Tieu K, Moodie CAS (2013) An application of nonlinear feature extraction - a case study for low speed slewing bearing condition monitoring and prognosis. 2013 IEEE/ ASME International Conference on Advanced Intelligent Mechatronics: Mechatronics for Human Wellbeing, AIM 2013

42. Hase A (2020) Early detection and identification of fatigue damage in thrust ball bearings by an acoustic emission technique. Lubricants. 8(3):37

Publisher's note Springer Nature remains neutral with regard to jurisdictional claims in published maps and institutional affiliations. 